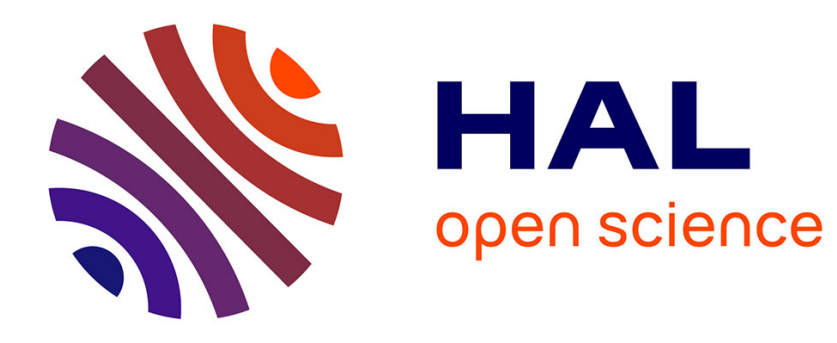

\title{
Sharma et l'essor du commerce islamique dans l'océan Indien occidental (Xe-XIIe siècle)
}

Eric Vallet

\section{To cite this version:}

Eric Vallet. Sharma et l'essor du commerce islamique dans l'océan Indien occidental (Xe-XIIe siècle). Axelle Rougeulle. Sharma. Un entrepôt de commerce médiéval sur la côte du Hadramawt (Yémen, ca 980-1180), Archeopress, p. 467-478, 2015. halshs-01298960

\section{HAL Id: halshs-01298960 \\ https://shs.hal.science/halshs-01298960}

Submitted on 6 Apr 2016

HAL is a multi-disciplinary open access archive for the deposit and dissemination of scientific research documents, whether they are published or not. The documents may come from teaching and research institutions in France or abroad, or from public or private research centers.
L'archive ouverte pluridisciplinaire HAL, est destinée au dépôt et à la diffusion de documents scientifiques de niveau recherche, publiés ou non, émanant des établissements d'enseignement et de recherche français ou étrangers, des laboratoires publics ou privés. 


\section{SHARMA}

\section{UN ENTREPÔT DE COMMERCE MÉDIÉVAL SUR LA CÔTE DU HADPRAMAWT (YÉMEN, $C A$ 980-1180)}

sous la direction de

\section{Axelle Rougeulle}

\section{Contributions de}

Vincent Bernard, Charlène Bouchaud, Annabelle Collinet, Rémy Crassard, Vladimir Dabrowski, Thibaut Deviese, Danièle Foy, Delphine Guillemare, Claire Hardy-Guilbert, Marie-Louise Inizan, Anne Joyard, Anne-Solenn Le hô, Noémie Martin, Audrey Peli, Martine Regert, Axelle Rougeulle, Mélanie Salque, Jérémie Schiettecatte, Margareta Tengberg, Eric Vallet, Bing Zhao 


\section{ARCHAEOPRESS PUBLISHING LTD \\ Gordon House \\ 276 Banbury Road \\ Oxford OX2 7ED}

www.archaeopress.com

ISBN 9781784911942

ISBN 9781784911959 (e-Pdf)

(C) Archaeopress and the individual authors 2015

All rights reserved. No part of this book may be reproduced, stored in retrieval system, or transmitted, in any form or by any means, electronic, mechanical, photocopying or otherwise, without the prior written permission of the copyright owners.

Printed in England by Holywell Press, Oxford This book is available direct from Archaeopress or from our website www.archaeopress.com 


\section{$\mathrm{V} / \mathbf{2}$. Sharma et l'essor du commerce islamique dans l'océan Indien occidental ( $\mathrm{x}^{\mathrm{e}}-\mathrm{XII}^{\mathrm{e}}$ siècle)}

L'étude du site de Sharma dans sa période de plus grande occupation s'apparente à bien des égards à une énigme historique. Le nombre insignifiant de ses mentions dans les textes apparaît en décalage total avec son importance commerciale, et l'on ne trouvera pas, dans les textes contemporains de description de sa fondation et de sa disparition, de son apogée et de son déclin (supra, Introduction). Dans les ouvrages géographiques d'al-Muqaddasī et d'al-Idrīsīe repris ensuite par des compilateurs plus tardifs comme Yāqūt al-Hamawī ou al-Dimashqī, seul le nom, « Sharma », apparaît, dans la liste des ports du Haḍramawt, aux côtés d'al-As'ā. Chez les deux auteurs les plus tardifs, l'introduction de ce toponyme apparaît même quelque peu anachronique puisque le site était déjà en net déclin ou abandonné à leur époque. Contrairement à d'autres ports de la côte sudarabique, ils n'ont d'ailleurs strictement rien à en dire et nul ne saura jamais de quelle manière les contemporains auraient qualifié l'ensemble des établissements de Sharma : sāḥil (rivage où il est possible de mouiller et de décharger), marsā' ou mukallāa (lieu de relâche pour les navires) ? balad ou qarya (village) ? À défaut de ces indications minimales, l'enquête historique ne peut en rester qu'à formuler des hypothèses à partir de divers indices contextuels, s'établissant à l'échelle locale, régionale et globale. Pris dans leur ensemble, ils composent par petites touches un tableau dans lequel l'occupation de Sharma entre le $\mathrm{x}^{\mathrm{e}}$ et le $\mathrm{XII}^{\mathrm{e}}$ siècle prend progressivement sens, et apparaît comme un maillon essentiel dans l'essor du commerce islamique sur le pourtour de l'océan Indien occidental au cours de cette même période ${ }^{1}$.

\section{V/2-1. Fragments d'histoire locale}

Première question : qui contrôlait le territoire environnant Sharma de la seconde moitié du $\mathrm{x}^{\mathrm{e}}$ siècle à la seconde moitié du XII ${ }^{\mathrm{e}}$ siècle, lorsque les divers magasins furent en

${ }^{1}$ Cette question a fait l'objet d'une journée d'étude organisée par l'UMR 8167 Orient et Méditerranée / Islam médiéval le 5 juin 2009 à Paris, et qui a réuni 11 spécialistes des différentes régions bordières de l'océan Indien occidental (David Bramoullé, Guy Ducatez, Claire Hardy-Guilbert, Mark Horton, Elizabeth Lambourn, Roxani Eleni Margariti, Valeria Fiorani Piacentini, Stéphane Pradines, Axelle Rougeulle, Eric Vallet, Bing Zhao). Un livre collectif élaboré à partir de cette journée, en cours de préparation sous le titre L'horizon Sharma, sous la direction d'A. Rougeulle et E. Vallet, présentera un panorama plus large et détaillé de l'histoire des échanges indo-océaniques de la période des $\mathrm{X}^{\mathrm{e}}$-XII ${ }^{\mathrm{e}}$ siècles. Le présent chapitre se concentre pour sa part sur les éléments historiques permettant d'éclairer directement l'histoire du site de Sharma. activité ? On ne dispose à ce sujet d'aucune certitude, mais de fortes présomptions.

Le site de Sharma se situe historiquement dans un ensemble vaste, s'étendant à l'est d'al-Shiḥr jusqu'à l'embouchure du Wādī Masīla, connu encore aujourd'hui sous le nom d'al-Mishqāṣ. Selon Bā Maṭraf, ce terme commun dans les langues sudarabiques anciennes signifie «l'est / orient » par opposition à $m i$ ' $r a \bar{b}$, « ouest / occident ». Il en serait venu à désigner la bande côtière, large de quelques kilomètres qui s'étendait d'al-Hāmī jusqu'au débouché du Wādī Masīla, à l'est de la ville d'al-Shị̣r². À cette dimension géographique du terme vient s'ajouter une dimension linguistique : al-mishqāșiyyūn, les « habitants d'al-Mishqāṣ » désignant, selon l'historien hadrami contemporain al-Malāhī, une population continuant de parler des dialectes sudarabiques ${ }^{3}$. Ce toponyme entérine donc, tout au moins au moment de son apparition, l'existence d'une césure entre la ville d'al-Shị̣r et la longue plaine littorale qui s'étend à l'est de la cité.

Les premières mentions de cette désignation géographique connues pour cette portion de territoire côtier remontent au $\mathrm{XIII}^{\mathrm{e}}$ siècle, ce qui n'exclut pas qu'il ait été utilisé de façon plus ancienne, mais les sources locales hadramies sont muettes à ce sujet. La plus ancienne chronique de l'histoire du Hadramawt en arabe accessible à ce jour, l'histoire de Shanbal (m. 920/1514), commence de manière abrupte au début du XII ${ }^{\mathrm{e}}$ siècle et ne mentionne le nom de Mishqāṣ qu'à partir du début du XIII ${ }^{\mathrm{e}}$ siècle (Shanbal 2003, p. 72). Rédigée au $\mathrm{XVI}^{\mathrm{e}}$ siècle, elle reprend une chronique légèrement antérieure aujourd'hui perdue ${ }^{4}$. Rien ne permet toutefois d'évaluer le degré de leur réécriture et de leur exactitude pour les périodes les plus anciennes. Il convient donc de rester prudent dans la datation de l'usage de ce terme avant le XIII ${ }^{\mathrm{e}}$ siècle.

Une source extérieure à la région, le Livre des revenus du sultan rasūlide al-Mu'ayyad Dāwūd (m. 721/1321), un

\footnotetext{
${ }^{2}$ Bā Mațraf 1983, p. 20 ; voir également al-Malāḥī 1989, p. 7 n. 7.

${ }^{3}$ Ibid., p. 7.

${ }^{4}$ Il s'agit du Ta'rīkh de Bā Ḥasan, auteur ayant vécu à Raydat al-Mišqāṣ et mort en 818/1415-1416. Cet ouvrage sous une forme manuscrite est cité par al-Hāmid 1968, sans que l'on sache avec précision à quel manuscrit il se réfère. Selon R.B. Serjeant, un manuscrit avait été rapporté par Freya Stark à la Bodleian Gallery, qui viendrait de la bibliothèque al-'Aț̣ās d'al-Hurayḍa (Serjeant 1962, p. 245), mais nous n'avons pu en retrouver jusqu’à présent la trace.
} 
« atlas » administratif et fiscal datant de la fin XIII ${ }^{\mathrm{e}}$ siècle, confirme toutefois l'usage bien ancré de ce terme à cette période. Il consacre un chapitre à la province d'al-Shiḥr (al-a'māl al-shihriyya), passée alors sous le contrôle de la puissante dynastie sultanienne des Rasūlides qui gouverna l'Arabie du Sud entre 626/1229 et 858/14545. Cet ouvrage mentionne deux régions situées à l'est d'al-Shị̣r, celles de Raydat al-Mishqāṣ et d'al-Hayrīj, qui contribuaient toutes deux aux ressources de l'État rasūlide. 7000 dinars de revenus fiscaux étaient alors tirés du secteur de Raydat al-Mishqāṣ « sur les champs et les palmeraies qui s'y trouvent, ainsi que les droits (wäjib) des navires venant de Maqdishūh (Mogadiscio) pour l'huile de poisson (șîfa)» et 5000 dinars de Hayrīj sur les « champs et les palmeraies » (Jāzim 2008, p. 134). Sur la carte de la province contenue dans le Livre des revenus, comme dans la chronique de Shanbal, ces « champs et palmeraies » qui entouraient les localités d'al-Rayda et Hayrīj sont désignés sous le nom de ghiyād, un terme utilisé communément dans le Haḍramawt pour désigner les zones cultivées, arrosées par irrigation et organisées autour des palmeraies (Jāzim 2008, p. 132 et 395). Le contrôle de ces ghiyā d fut souvent disputé pendant la période rasūlide et il constituait encore un enjeu important dans la première moitié du $\mathrm{XX}^{\mathrm{e}}$ siècle $^{6}$.

L'abondance des ressources souterraines en eau (voire en eau chaude, comme à al-Hāmīi), l'irrigation de surface ou de versant (système des ghayl) explique la présence d'importantes zones cultivables dans le lit et dans les environs des principaux wadis qui entaillaient le plateau désertique (najd) de l'arrière-pays pour rejoindre la mer. Certains de ces wadis étaient de ce fait des axes de circulation privilégiés vers l'intérieur, pour rejoindre le Wādī Haḍramawt proprement dit et ses principales cités, Shibām et Tarīm, situées à près de $200 \mathrm{~km}$ du littoral. Nul hasard, donc, si al-Shihr et ses environs immédiats, al-Rayda et Hayrīj, constituaient les trois pôles principaux dans cette région à la fin du Moyen Âge. Chacun de ces sites se trouvait au débouché des grands axes liant la côte au grand Wādī intérieur : les Wādī Daw‘an, Wādī al-Mi'dā et Wādī 'Irif en constituaient les routes principales depuis al-Shihrr ; le Wādī Ma'bar depuis al-Rayda, et le Wādī Masīla depuis Hayrīj (al-Malāḥ̄ 1989, p. 9). Ces trois localités étaient également entourées de plaines fertiles, occupées par la végétation dense des ghiyā $d$ qui s'étendait sur moins d'une dizaine de kilomètres entre la côte et les premiers reliefs conduisant aux plateaux du najd. Au moment où Sharma disparaît au XII siècle, l'espace de la côte hadramie apparaît ainsi largement structuré par ces trois localités.

L'histoire de cette région reste encore largement à écrire et les sources pour les périodes les plus anciennes sont bien maigres. Al-Shihrr (dénommée également au cours du Moyen Âge al-As‘ā, voir chapitre V/1) et Hayrīj, situés chacun à l'une des extrémités du Mishqāṣ, sont les premiers lieux qui apparaissent dans les sources arabes et consti-

\footnotetext{
${ }^{5}$ Sur l'histoire de la côte du Hạạramawt sous domination rasūlide, voir Vallet 2010, p. 240-248 et 608-627.

${ }^{6}$ Shanbal 2003, par exemple p. 148, 151 (voir la traduction de Guy Ducatez dans Hardy-Guilbert 2004, p. 116).
}

tuaient apparemment les deux territoires les plus actifs de ce secteur au cours des premiers siècles de la période médiévale. Le géographe yéménite al-Hamdānī, qui décrit de façon assez précise la côte de l'Arabie du Sud dans la première moitié du $\mathrm{x}^{\mathrm{e}}$ siècle n'évoque d'ailleurs aucune autre localité qu'al-Hayrīj et al-As‘ā pour cette portion de la côte ${ }^{7}$. Des vestiges importants, ainsi que du matériel des $\mathrm{IX}^{\mathrm{e}}-\mathrm{X}^{\mathrm{e}}$ siècles ont été retrouvés sur une partie du site de Hayrīj, ce qui confirme le rôle qu'il joua dès l'époque abbasside, et peut-être même avant (Rougeulle 2008, p. 380-381). L'antiquité du site d'al-As' ‘ā/al-Shihrr est également bien établie (supra, ch. V/1-3 Hardy-Guilbert 2004).

Il faut attendre en revanche le début du XIII ${ }^{\mathrm{e}}$ siècle pour que le nom d'al-Rayda apparaisse dans une source arabe. Il est alors mentionné comme une simple étape entre al-Shihrr à l'ouest, et Hayrīj à l'est, sur l'itinéraire côtier qui conduit d'Aden à la région du Dhofar (Ibn al-Mujāwir 1951, p. 268-270). Les prospections menées par Axelle Rougeulle sur le site actuel de Rayda ont bien retrouvé du matériel importé datant des $\mathrm{X}^{\mathrm{e}}-\mathrm{XII}^{\mathrm{e}}$ siècles, prouvant que le site servait déjà de mouillage à cette époque, même si la nature de l'établissement humain qui s'y trouvait à cette date n'a pu être établie (Rougeulle 1999, p. 130). Par la suite, al-Rayda joua un rôle central dans le contrôle du Mishqāṣ. Au XIV e siècle, une forteresse (huṣn) s'y trouvait, et peut-être aussi une enceinte (Shanbal 2003, p. 148). On apprend en effet que la petite cité dut subir plusieurs sièges entre le $\mathrm{XIII}^{\mathrm{e}}$ et le $\mathrm{XV}^{\mathrm{e}}$ siècle, à moins que ceux-ci n'aient affecté que la forteresse (Shanbal 2003, p. 72). Al-Rayda était également visitée par des navires venant de la côte d'Afrique de l'Est et servait de relais pour la navigation de cabotage le long de la côte hadramie, servant ainsi d'étape intermédiaire entre al-Shihrr et Hayrīj. L'occupation de Sharma et le développement d'al-Rayda à partir du $\mathrm{x}^{\mathrm{e}}$ siècle constituent de fait les deux principaux indices que la côte du Mishqāṣ devint plus fréquentée à partir de cette période, un phénomène que l'on pourrait peut-être relier à la mise en valeur plus importante de la plaine littorale et la constitution ou l'essor de ses ghiyād. Il reste toutefois à identifier qui ont pu être les acteurs de cette évolution.

En l'absence de toute indication précise dans les sources médiévales, nous n'avons d'autre choix que de partir des traditions conservées localement. L'histoire d'al-Mishqāṣ aux XIX ${ }^{e}$ et $X^{e}$ siècles est étroitement associée au nom d'une tribu, al-Ḥumūm (ou al-Uḥmūm). Al-Malāḥ̄i, un érudit local vivant encore aujourd'hui dans la ville d'al-Shihr, a consacré une monographie historique à l'histoire de cette confédération tribale à l'époque des sultans qu'ayți de Mukallā, entre 1867 et 1967, étude enrichie de descriptions précises de leur mode de vie, de leurs activités et de leurs coutumes au milieu du Xx ${ }^{\mathrm{e}}$ siècle (al-Malāhī 1989). Le territoire contrôlé par cette confédération à l'époque moderne s'étendait à la fois sur les premiers plateaux (najd), et sur les étendues côtières, même si tous ces espaces n'étaient pas directement

\footnotetext{
7 Al-Hamdānī 1884, p. 51 et 1983, p. 90-91. Hayrīj est également mentionné par Ibn Khurradādhbih 1889, p. 138 et apparaît dans le Livre des merveilles de l'Inde (Van der Lith \& Devic 1883-1886, § 116 ; Sauvaget 1954, p. 297).
} 
la propriété de membres de la tribu. Dans un dictionnaire des lieux du Haḍramawt rédigé au cours de la première moitié du $x^{e}$ siècle, le savant hadrami 'Abd al-Raḥmān al-Saqqāf dresse un tableau détaillé de la composition de cette confédération, divisée alors en une dizaine de clans, et regroupant environ 4000 hommes en arme (al-Saqqāf 2002, p. 100). La plupart des clans étaient en réalité établis dans la zone de piémont, sur les principaux wadis contrôlant l'accès à l'intérieur, suivant un mode de vie sédentaire ou semi-nomade. Les clans de Humūm installés sur la plaine côtière étaient plus rares. Ils y côtoyaient d'autres groupes tribaux de taille plus réduite, qui leur étaient soumis. Dans la première moitié du $\mathrm{Xx}^{\mathrm{e}}$ siècle, les Humūm prélevaient pour leur compte la kìla (redevance en grains), la sharāha (redevance sur les palmeraies), le judūh (redevance sur la pêche) et la khafāra (droit de protection payé par les navires marchands), même s'ils devaient parfois partager ces ressources avec d'autres groupes (al-Malāhịi 1989, p. 49-50).

Diverses autorités locales font des Humūm une tribu ancienne, établie dans la région dès la fin de la période antique sudarabique. Selon al-Malāḥ̄, les Humūm étaient constitués par le rassemblement de plusieurs clans d'origine différente au départ, autour des Āl 'Amr b. Dhī Jadn, et de leur principal lignage Bayt 'Alī (ou Banū 'Alī), ayant pour ancêtre éponyme Haḍramawt (al-Malāḥ̄ 1989, p. 1-4). Un récit rapporté localement, et que reprend al-Malāḥ̄, place notamment Sharma au centre de l'alliance passée entre le clan de Bayt 'Alī et un autre clan, venu de l'ouest, Bayt Ghurāb, qui se rattachait à un ancêtre éponyme différent, Tayy ${ }^{8}$. Au point de départ de cette histoire se trouve la figure de 'Alī, chef des Humūm, assassiné à une date indéterminée par un chef de la tribu himyarite de Sibyān (appelée également dans le récit traditionnel Bā Qurayḍa ou Qurayẓa). Qaḥțān, fils de 'Alī, envoya alors son propre fils, 'Ajlān, auprès des Bā Qurayẓa pour demander la punition du meurtrier, mais ceux-ci l'emprisonnèrent et se moquèrent de son jeune âge. Libéré, 'Ajlān rencontra deux hommes des Banū Ghurāb alors qu'ils se trouvaient au bord de la mer, à Sharma, et leur demanda assistance. L'un d'entre eux partit tuer le meurtrier de son grand-père tandis que l'autre prononçait une phrase restée dans les mémoires «'Ajlān est digne de cette demande » ('āzah 'ajlān bad'), ce qui était une façon de signifier leur alliance. En contrepartie de l'aide qu'il avait reçu, 'Ajlān leur garantit le bénéfice du territoire de Sharma, le village de Halfūn et le Wādī Dubba, ainsi que le tiers de ce que les Banū 'Alī percevaient sur les grains (kīla) et sur la protection des navires et des voyageurs (khafāra). Ce traité d'alliance était encore en vigueur dans la première moitié du $\mathrm{Xx}^{\mathrm{e}}$ siècle selon al-Malāhị $\overline{1}^{9}$.

Cette « légende de Sharma » a tout d'un récit fondateur, comme l'imaginaire généalogique arabe en a forgé

\footnotetext{
${ }^{8}$ Bā Mațraf fait venir le clan des Bayt Ghurāb de la localité Qan̄̄', site $\mathrm{du}$ fameux port préislamique niché au pied d'un cône volcanique connu sous le nom de Huṣn al-Ghurāb (citadelle des corbeaux). Il s'agit toutefois peut-être simplement d'un rapprochement dû à la similarité des deux noms (Bā Mațraf 1983, p. 20).

${ }^{9}$ Al-Malāḥi 1989, p. 10-11. Voir également un récit proche dans Bā Mațraf 1983, p. 20.
}

tant d'autres. Il avait pour but d'inscrire dans la durée le rapport de force qui s'était instauré à un moment donné sur le terrain, entre des clans établis dans les piémonts et sur les plateaux (Bayt 'Alī), et d'autres sur la plaine littorale (Bayt Ghurāb). Il est difficile de préciser à quelle période de telles relations ont pu s'établir. Si le nom des Humūm n'apparaît pas dans la chronique médiévale de Shanbal, on peut relever en revanche que les Āl 'Amr b. Dhī Jadn, auquel appartient le clan de Bayt 'Alī, sont cités par al-Hamdānī au $\mathrm{X}^{\mathrm{e}}$ siècle : ils occupent alors déjà une place stratégique sur la route entre al-As 'ā et l'intérieur du Wādī Haḍramawt dans l'espace des piémonts (al-Hamdānī 1884, p. 85). Leur présence sur près d'un millénaire dans cette zone de passage apparaît ainsi comme une constante forte de l'histoire de la région et il n'est pas impossible que le clan de Bayt 'Alī ait dès la période médiévale affirmé des velléités d'exercer une forme de suzeraineté sur la zone littorale, sans pour autant quitter les piémonts qui constituaient le cœur de leur territoire.

Si la présence des Bayt 'Alī dans la zone des piémonts paraît un fait bien établi, le peuplement de l'espace littoral présente en revanche une situation plus complexe. Pour al-Hamdān̄̄ au $\mathrm{X}^{\mathrm{e}}$ siècle, les Mahra occupent manifestement une position dominante dans l'espace littoral hadrami. Mais il n'en va plus ainsi deux siècles plus tard : alors qu'al-Hamdān̄ indique qu'al-As‘ā/al-Shiḥr était sous la domination d'un chef mahri au $x^{\mathrm{e}}$ siècle, la localité portuaire apparaît à partir du milieu du $\mathrm{XI}^{\mathrm{e}}$ siècle sous la domination d'un clan affilié aux Kinda, les Āl Iqbāl, venus de l'intérieur du Wādī Haḍramawt (al-Ḥāmid 1968, p. 424-428). C'est au cours de ces deux siècles, entre $x^{\mathrm{e}}$ et $\mathrm{XII}^{\mathrm{e}}$ siècles, que les Mahra semblent amenés à se replier vers les côtes situées à l'est du Wādī Masīla ${ }^{10}$. L'établissement des Banū Ghurāb dans le secteur de Sharma date-t-il de cette période ? Rien ne permet de le confirmer. Ajoutons à cela que, dans son étude, al-Malāhī mentionne également un clan connu sous le nom d'al-Sibā'ī, installé à l'époque moderne à al-Dīs, dans le petit port d'al-Qarn, et dans les villages des environs, qui était lié par traités avec les Ḥumūm et percevait la khafāra sur les navires. Al-Malāḥ̄ suggère sur la base de récits oraux que leur présence aurait été plus ancienne que celle des Humūm et que ce groupe aurait également été établi à Sharma à une époque non précisée (al-Malāhīi 1989, p. 15 et 50).

Sibā‘̄i ? Bayt Ghurāb ? Il est impossible en l'état actuel des données de dire quelles populations se trouvaient dans les environs de Sharma entre le $\mathrm{X}^{\mathrm{e}}$ et le $\mathrm{XII}^{\mathrm{e}}$ siècle, ni de préciser si ce territoire se situait déjà dans l'horizon d'influence de clans tribaux établis sur les piémonts. On notera simplement pour l'instant que l'histoire locale de Sharma doit être appréhendée à deux échelles au moins.

Une première échelle est constituée par le micro-territoire désigné dans la légende de Sharma comme la «part »des Banū Ghurāb : Sharma, le Wād̄̄ Jarba, avec les villages de Yaḍghat et Halfūn, dont les liens entre $\mathrm{x}^{\mathrm{e}}$ et $\mathrm{XII}{ }^{\mathrm{e}}$ siècles

\footnotetext{
${ }^{10}$ Voir également « Mahra », $E I^{2}$.
} 
apparaissent clairement d'un point de vue archéologique (chapitre $\mathrm{V} / 1$ ). Ce périmètre étendu sur moins d'une vingtaine de kilomètres possède une indéniable unité géographique : enserré par l'avancée du plateau rocheux, il constitue une sorte d'enclave interrompant la plaine côtière. La vallée de Jarba, mise en culture grâce à des systèmes d'irrigation développés était l'arrière-pays immédiat de Sharma au Moyen Âge, fournissant non seulement tout ou partie des céréales et des dattes consommées à Sharma, mais aussi les objets en céramique cuits dans les fours de Yaḍghat, également exportés au-delà de Sharma. La production céramique de Yaḍghat a largement précédé l'installation du comptoir marchand, puisque les fours étaient déjà en activité dès la période abbasside (chapitre $\mathrm{V} / 1$ ), mais lorsque l'entrepôt a vu son activité s'étendre, cela s'est fait sans rupture avec l'arrière-pays immédiat, mais au contraire dans une forte continuité avec lui.

Une seconde échelle, plus large, est définie par le territoire du Mishqāṣ, contrôlé par divers groupes tribaux qui revendiquaient de percevoir des revenus sur les activités maritimes. Sur le modèle de la répartition esquissée dans la « légende de Sharma », on peut envisager que les navires qui mouillèrent au large de cette baie entre le $\mathrm{x}^{\mathrm{e}}$ et le $\mathrm{XII}^{\mathrm{e}}$ siècle aient eu à verser un droit de protection à la fois aux clans installés dans le Wādī Yaḍghat et à un ou plusieurs autres clans établis plus loin, dans la zone des piémonts. Il reste toutefois difficile d'évaluer les liens matériels qui pouvaient exister entre Sharma et l'espace des piémonts.

Au-delà de ces hypothèses, un fait est certain : l'absence de système défensif significatif tourné vers l'intérieur des terres, de même que les liens économiques établis avec l'environnement immédiat montrent que les habitants de Sharma n'eurent pas à craindre de menace venant de cette direction entre la fin du $\mathrm{X}^{\mathrm{e}}$ et le milieu du XII ${ }^{\mathrm{e}}$ siècle et qu'ils purent développer leurs activités maritimes et entreposer leurs marchandises, sans craindre les menées de clans tribaux locaux, ce qui implique la stabilité, au moins relative, de la carte tribale au cours de cette période, et le maintien de liens humains et matériels importants. Outre l'approvisionnement en grains (sorgho et blé) et en dattes (chapitre III/10), il est probable que de la main d'œuvre venant de l'arrière-pays ait été employée, pour la construction des entrepôts, la manutention des marchandises, ou pour des tâches artisanales dont il reste quelques traces matérielles (chapitre III/8).

La chronique de Shanbal fait certes état de conflits incessants dans le territoire du Mishqāṣ, mais l'on se situe alors dans la seconde moitié du $\mathrm{XII}^{\mathrm{e}}$ siècle, à un moment où le lignage des Āl Iqbāl, qui dominait le port d'al-Shiḥr/ al-As'ā depuis la seconde moitié du XI ${ }^{\mathrm{e}}$ siècle revendiquait avec force le contrôle du Mishqāṣ. D’un récit assez confus, on retiendra simplement ici l'affrontement des Āl Iqbāl avec le clan des Thā'in (allié à l'époque moderne aux Humūm), établis autour de Raydat al-Mishqāṣ au tournant des $\mathrm{XII}^{\mathrm{e}}$ et $\mathrm{XIII}^{\mathrm{e}}$ siècles. Ces affrontements culminèrent en 606/1209-1210 lorsque le maître d'al-Shiḥr Rāshid b. Iqbāl et son fils Fāris furent tués par des hommes de Thā'in dans un affrontement armé près de Rayda (Shanbal 2003, p. 48, 71 ; al-Hāāmid 1968, p. 425). Dès cette époque, on voit donc apparaître une configuration qui n'est pas sans rappeler celle des $\mathrm{XIX}^{\mathrm{e}}-\mathrm{XX}^{\mathrm{e}}$ siècles, dominée par les tentatives infructueuses menées depuis al-Shihr pour contrôler le Mishqāṣ et ses ghiyād, contre des clans locaux. Dans quelle mesure ces affrontements eurent-ils un impact sur l'histoire de Sharma? Ne peut-on y voir l'un des facteurs qui précipita l'abandon des entrepôts portuaires ? Cette hypothèse ne peut être écartée.

On retiendra donc, à titre de conclusion provisoire, que l'histoire de Sharma peut être replacée dans le contexte de l'affirmation lente de la région côtière du Mishqāṣ entre $\mathrm{x}^{\mathrm{e}}$ et $\mathrm{XII}^{\mathrm{e}}$ siècles. Au cours de cette période, la cité d'al-As' $\bar{a} /$ al-Shiḥr en vient à se distinguer, à partir du règne des $\overline{\mathrm{A}} \mathrm{l}$ Iqbāl au plus tard, du territoire situé à l'est, une césure que signifie à sa manière l'usage du terme de mishqās pour désigner ces terres orientales à partir de cette période. Ce territoire devient à partir de la seconde moitié du XII siècle au plus tard, l'enjeu de luttes entre les maîtres d'al-As' $\bar{a} /$ al-Shihrr et des clans établis localement. Le port de Rayda sort véritablement de l'ombre au moment même où disparait le site de Sharma. Site côtier, Rayda était également au centre d'une zone fertile de ghiyād, et constituait un point commode pour le contrôle de la circulation terrestre et maritime. Tel n'était pas le cas de Sharma, site isolé, qui ne constituait ni un carrefour de circulation, et ni un accès aux ghiyā d, dont il était séparé par une importante zone aride. À l'époque qu'ayțī encore, Sharma était, selon 'Abd al-Raḥmān al-Saqqāf, un lieu d'embarquement semiclandestin pour les voyageurs qui ne pouvaient payer les taxes de sortie à al-Shiḥr ou al-Mukallā, en direction de Sayhūt (Mahra) ou des côtes africaines (al-Saqqāf 2002, p. 102). Vu de l'intérieur des côtes, Sharma restait un endroit marginal, que l'on pouvait se contenter de contrôler de loin. Du point de vue des logiques d'occupation du territoire visibles sur la longue durée dans la région, concentrées autour des zones fertiles des wadis et des piémonts, la présence d'un site important à Sharma entre le $\mathrm{x}^{\mathrm{e}}$ et le XII siècle, apparaît à bien des égards comme une anomalie, qui ne peut trouver son explication que dans une impulsion venue de gens de mer.

\section{V/2-2. Les fonctions d'un entrepôt marchand}

Plusieurs cas de fondation ou de refondation de sites côtiers sur la côte de l'Arabie sont attestés au cours de la période médiévale. Les plus connus d'entre eux résultent de la volonté d'un pouvoir étatique fort, désireux d'avoir un débouché maritime (création de Jeddah au premier siècle de l'Hégire) ou de renforcer la défense et la protection d'une cité côtière (cas de Zafār, refondée en 619/1221 par Aḥmad b. Muḥammad al-Habūḍ̄i (Vallet 2010, p. 609), ou de Hormuz, « déplacée » sur l'île de Jarūn en 699/1300 (Aubin 1953, p. 89-99) à l'initiative du Turc Bahā' al-Dīn Ayāz. Tel n'est manifestement pas le cas de Sharma, dont la vocation défensive ne s'est développée que tardivement, et qui ne présente pas les traits ordinaires d'une fondation princière, mais plutôt d'un relais commercial maritime, établi pour des marchands, et sans doute également par des marchands. 
L'étude archéologique a permis de mettre en lumière le fait qu'il ne s'agissait pas d'une véritable ville portuaire (chapitre II/1) : les bâtiments sont tous construits sur un plan similaire, dépourvus de toute décoration intérieure et leur répartition ne paraît pas révéler une véritable intention urbanisatrice ; des quantités importantes de céramique, détachées pour la plupart de tout usage domestique, identifient ces édifices avec des magasins. Seuls se distinguent dans cet ensemble une mosquée de taille réduite, peut-être entourée d'un petit $s \bar{u} q$, et un bâtiment aux parements de pierre plus soignés, sans doute à vocation officielle. Cette urbanisation limitée contraste avec ce que l'on peut observer dans les ports contemporains de l'Arabie ou du pourtour de l'océan Indien, tels qu'ils sont connus par l'archéologie ou par les textes.

Une comparaison suggestive peut être établie avec le port d'Aden, dont la topographie et le fonctionnement ont été récemment mis en lumière grâce aux documents de la Geniza du Caire, contenant notamment des fragments significatifs de la correspondance des marchands juifs établis à Aden entre la fin du $\mathrm{XI}^{\mathrm{e}}$ et le début du XIII ${ }^{\mathrm{e}}$ siècle (Margariti 2007 ; Goitein \& Friedman 2008). S'il est impossible d'évaluer précisément sa superficie et la taille de sa population au cours de cette période, Aden se présente comme une véritable cité, dominée par deux forteresses qui contrôlent, pour la première le passage vers le continent (al-Ta'kar), et pour la seconde les abords maritimes (al-Khaḍrā'). Le front maritime est protégé par un petit mur surmonté de roseaux tressés, qui offre une protection aux maisons les plus proches de la mer contre les vagues et le vent, et permet de masquer en partie la ville aux assaillants. Il faut attendre la fin du XII ${ }^{\mathrm{e}}$ siècle pour qu'une véritable muraille, percée de plusieurs portes vienne séparer la ville de la plage (Margariti 2007, p. 87-94). Aux XI $\mathrm{e}^{\mathrm{e}}-\mathrm{XII}{ }^{\mathrm{e}}$ siècles, deux espaces officiels (peut-être composés de plusieurs bâtiments) sont les lieux essentiels où s'opère le contrôle de l'État sur les flux du commece : la furḍa, douane proprement dite où les marchandises sont taxées à l'importation et l'exportation; le magasin connu sous le nom d'al-dār al-sa 'īda, qui servait à la revente en gros des marchandises arrivées de la mer, sous contrôle de l'administration.

Mais les grands marchands d'Aden, comme Maḍūn b. Japheth, chef de la communauté juive locale, en lien avec de nombreux partenaires en Égypte et en Inde dans la première moitié du $\mathrm{XII}^{\mathrm{e}}$ siècle, possédaient également ailleurs en ville des magasins et divers lieux de stockage, parfois confondus avec leur propre demeure. Dans une lettre, l'un de ces marchands présents à Aden, Khalaf b. Ishāa, signale ainsi que du fer, repêché à la suite d'un naufrage au large de la côte arabique, a été déposé dans la demeure $(d \bar{a} r)$ de " l'illustre shaykh Maḍmūn » (Margariti 2007, p. 100). Dans le premier tiers du $\mathrm{XIII}^{\mathrm{e}}$ siècle, le voyageur Ibn al-Mujāwir décrit d'ailleurs les demeures marchandes d'Aden comme possédant toutes deux niveaux : « en bas, des magasins (makhāzin) et en haut des salles de réception (majālis) en pierre et en plâtre (juṣs) » (Ibn al-Mujāwir 1951, p. 137), une répartition sans doute valable également pour le siècle qui précède. Les lettres de la Geniza ont gardé la trace des frais de location de magasins engagés par certains marchands lors de leur passage à Aden, ou à distance. Dans une lettre envoyée depuis l'Inde, le marchand juif Isḥāq b. Makhlūf évoque ainsi le sort de balles de tissus expédiées vers Aden, à stocker dans le magasin de Maḍmūn en attendant qu'il puisse en tirer meilleur prix (Margariti 2007, p. 195). L'accumulation de marchandises de provenance diverse, souvent durant de longues périodes, apparaît comme un trait récurrent de ces dépôts. Certains marchands s'en plaignent d'ailleurs dans leurs lettres ou en tirent argument pour se justifier de leurs manquements : en 1098, un autre marchand juif, Joseph al-Lebdī, incapable de fournir le livre de compte qui lui est réclamé, affirme qu'il a été probablement égaré dans le magasin d'un certain Jekuthiel, sous des sacs d'indigo (Margariti 2007, p. 196). Au total, les magasins occupaient une place suffisamment importante dans la cité pour que, lors d'une guerre civile survenue en 1137-1138, ils se retrouvent en première ligne : «les demeures furent brûlées et les magasins (makhāzin) pillés », selon le témoignage d'un marchand présent sur les lieux (Margariti 2007, p. 195).

Les documents conservés à propos d'Aden offrent ainsi un tableau vivant de ce que pouvait être la fonction d'entrepôt d'une grande cité portuaire des $\mathrm{X}^{\mathrm{e}}-\mathrm{XII}^{\mathrm{e}}$ siècles, où la responsabilité était partagée entre l'État et les acteurs privés du commerce. Les modalités d'usage des nombreux magasins retrouvés à Sharma étaient-elles foncièrement différentes de celles qui prévalaient à Aden ? Si la présence de magasins gouvernementaux ne peut guère être établie dans le cas du port hadrami, on retiendra plutôt ici la figure de ces marchands locaux gérant des magasins situés dans leur demeure ou loués ailleurs dans la cité. À Aden, Roxani Margariti a bien mis en lumière le rôle de pivot que pouvait jouer un personnage comme Maḍun̄ b. Japheth, désigné dans certains textes par le nom de wakīl, représentant de marchands, pour le compte desquels il gérait l'importation, le stockage, la vente ou l'exportation de leurs biens. À côté de partenaires réguliers, qui constituaient le cœur du réseau marchand de Maḍmūn, venait s'ajouter un nombre important de contacts occasionnels, marchands de passage à Aden ou partenaires éphémères, auxquels il était amené à rendre des services, comme le fait d'entreposer des marchandises chez lui, ou dans des espaces pris ailleurs en location. À Aden, il ne suffisait que d'un petit nombre de résidents permanents pour assurer la circulation - plus ou moins fluide - des biens et des richesses d'un nombre élevé d'acteurs des échanges.

Il en allait sans doute de même à Sharma, où le nombre important de magasins, tout particulièrement au cours de la phase IV, n'impliquait pas nécessairement la présence de plusieurs dizaines de marchands sur place. Grâce aux dispositifs de communication formels et informels (contrats, lettres) courants dans le monde marchand islamique médiéval, un petit nombre de marchands, de statut libre ou servile, en lien avec des partenaires stables ou occasionnels, était à même de gérer des flux commerciaux conséquents dans l'entrepôt. Si Sharma différait d'Aden par son caractère urbain peu prononcé et par l'absence de bâtiments centraux qui constituaient la marque de l'État (douane), on peut faire l'hypothèse que le fonctionnement 
des magasins de Sharma se rapprochait de celui de l'entreposage privé tel qu'il apparaît à Aden.

L'étude archéologique de Sharma a toutefois révélé l'existence d'un bâtiment différent des autres, B36. Situé dans le « quartier de la corniche », non loin du port et de la mosquée, et agrandi au cours du $\mathrm{XI}^{\mathrm{e}}$ siècle, sa construction en pierre de taille fit l'objet d'un soin particulier, sans dépasser toutefois les autres magasins par sa taille (chapitre II/5). S'agissait-il de la résidence de celui qui exerçait l'autorité sur le port ? ou d'un bâtiment à caractère officiel ? mais pour remplir quelle fonction dans ce cas ? On manque ici de points de comparaison contemporains de Sharma. L'exemple d'Aden, éclairé par les documents de la Geniza et par la description d'Ibn al-Mujāwir, montre la présence d'une administration assez nombreuse chargée de la perception des taxes, sous l'autorité de "shaykhs de la douane », mashā'ikh al-furda, placés sous l'autorité directe des maîtres de la ville, mais on se situe alors dans le cadre d'une cité-État naissante, ce qui n'est pas le cas de Sharma (Margariti 2007, p. 115-119).

Un autre modèle se dégage toutefois sur la côte indienne. Une inscription en sanscrit retrouvée à Panjim (région de Goa) atteste par exemple l'activité d'un certain Chadama, qui se voit reconnu en 1053 le droit de prélever des taxes sur les navires entrant dans le port pour financer la construction d'une mijigiti (mosquée). Six ans plus tard, en 1059, une autre inscription mentionne le même personnage, en précisant qu'il était le fils de Madhumada (Muhammad), fil de Aliyama ('Alī), un marchand persan (tājika) venu du port de Saymūr (Flood 2009, p. 23). Cette forme de délégation de l'autorité fiscale à un marchand, musulman ou non, apparaît très courante à partir du XIII ${ }^{\mathrm{e}}$ siècle au plus tard, avec l'institution du shāhbandar (« maître du port »), qui renvoyait aux dires d'Ibn Batțūṭa (XIV ${ }^{\mathrm{e}}$ siècle) à la fois au « chef des marchands » à Calicut, et était en même temps le « chef des musulmans » vivant dans la cité de Quilon, dans le sud de l'Inde (Ibn Battūta 1853-1859, IV, p. 100 et 186). Responsable de la perception des taxes dans le port, de la délivrance des autorisations d'arrivée et de départ, le shāhbandar occupait également, dans le cas des cités non-islamiques de l'Inde, le rôle de chef de la communauté musulmane. Sharma disposait-elle également d'une sorte de shāhbandar, d'une autorité supervisant le port et prélevant une taxe pour l'entretien de la mosquée - et du personnel qui lui était sans nul doute attaché - ou pour verser aux tribus locales la redevance due au titre de la khafāra? Il est impossible d'en apporter la preuve décisive mais un tel mode de fonctionnement apparaît plausible. À Goa, la fondation d'une mosquée accompagna la fixation d'une lignée de marchands-armateurs, vraisemblablement originaires du golfe Arabo-Persique, et le développement des activités portuaires sous l'égide de cette famille. Aurait-il pu en être de même dans le cas de Sharma?

\section{V/2-3. Des marchands sirafis, à l'origine de Sharma ?}

Nous ne sommes pas entièrement dépourvus de témoignages textuels sur l'activité « urbanisatrice » des grandes lignées marchandes venus du Golfe sur le pourtour de l'Arabie médiévale, mais ils doivent être traités avec précaution.

L'action bâtisseuse des «Persans » ('Ajam ou Furs), désignés aussi sous le nom de Sìrāfí, est principalement évoquée par un texte tardif par rapport à la période de Sharma, mais essentiel à bien des égards : le Ta'rīkh al-mustabṣir d'Ibn al-Mujāwir, un voyageur lui-même d'origine persane qui circula dans la Péninsule et en mer d'Arabie dans les années 610-620/1210-122011. Dans plusieurs passages, cet auteur évoque clairement le rôle des Sirafis dans l'activité des ports du pourtour de l'Arabie, notamment à la suite de la « ruine de Sīrāf », au moment du grand tremblement de terre qui toucha la cité plusieurs jours durant en 977. Outre cet événement qui fit que « les gens de Sīrāf se déplacèrent vers tous les rivages de la mer » (Ibn al-Mujāwir 1951, p. 43), Ibn al-Mujāwir évoque également un autre moment de dispersion de ces Sirafis en divers points de la mer Rouge, dans la seconde moitié $\mathrm{du} \mathrm{XI}^{\mathrm{e}}$ siècle, quand ils durent quitter le port de Jeddah en raison de la pression des chérifs et des tribus voisines. Ces migrations sirafies sont très clairement associées dans l'esprit d'Ibn al-Mujāwir à la fondation - ou la refondation - de sites côtiers, que notre auteur évoque en détail principalement pour la côte arabique de la mer Rouge.

Dans deux cas, Ibn al-Mujāwir décrit même précisément la geste bâtisseuse des Sirafis. À Ghulāfiqa, principal port de la ville yéménite de Zabīd entre le $\mathrm{IX}^{\mathrm{e}}$ et le XII ${ }^{\mathrm{e}}$ siècle, il rapporte que deux frères originaires de Sīrāf édifièrent de belles maisons et des mosquées en pierre de corail ( $k \bar{a} s h \bar{u} r)$, ainsi qu'un beau minaret paré de panneaux en bois de teck, qui finirent par être transportés dans la célèbre mosquée des Ashā'ir à Zabīd (Ibn al-Mujāwir 1951, p. 240). Dans le cas du site voisin d'al-Ahwāb, la description s'apparente même à celle d'une petite ville-champignon, surgie brutalement sur le rivage de la mer Rouge à l'initiative d'un grand marchand et patron de navire $(n \bar{a} k h \bar{u} d h \bar{a})$ :

« Abū al-Qāsim Rāmisht b. Shīrwīh b. al-Ḥusayn

b. Ja'far al-Fāris̄i construisit al-Ahwāb en 532/1137-1138, lorsqu'il vint de l'Inde pour faire le pèlerinage ; il en fit une belle ville (madina), possédant ses marchés, sa grande mosquée et ses magasins. Il y fit transporter le bois de teck depuis l'Inde. » (Ibn al-Mujāwir 1951, p. 246)

Une création ex nihilo, centrée autour d'une mosquée, d'un $s \bar{u} q$ et d'entrepôts : le parallèle avec Sharma est ici frappant. On verra plus loin que le personnage à l'origine de cette nouvelle fondation est bien connu par ailleurs, et qu'il représentait aux yeux de ses contemporains le modèle même (et peut-être le dernier) des marchands sirafis. Pour Ibn al-Mujāwir, le rôle des Sirafis dans l'édification de comptoirs côtiers plus ou moins éphémères ne fait guère de doute et s'il n'offre de précisions significatives que sur leurs dernières implantations (al-Ahwāb), cette activité

\footnotetext{
${ }^{11}$ Présentation du personnage et de l'œuvre dans Smith 2007.
} 
urbanisatrice s'étale sur une longue période allant du $\mathrm{X}^{\mathrm{e}}$ siècle au moins, au début du XII ${ }^{\mathrm{e}}$ siècle. Les Sirafis d'Ibn al-Mujāwir apparaissent ainsi comme de bons candidats pour l'attribution de la fondation du site côtier de Sharma.

Ces mouvements de migration et de « colonisation » de sites côtiers, ou d'établissement de comptoirs, ne sont pas sans lien avec l'évolution des principaux réseaux maritimes, identifiés dans la géographie d'Ibn al-Mujāwir à la chronologie des grands ports de la mer d'Arabie. Cet auteur distingue en effet quatre périodes, qui correspondent à quatre modes d'organisation des réseaux de navigation différents et successifs : une première période (A) dominée par le port de Raysūt (situé sur la côte actuelle du Dhofar) ; une seconde (B) caractérisée par la fortune du port de Șuhāar (côte de l'Oman) ; une troisième $(\mathrm{C})$ marquée par la prospérité des ports d'al-Tīz et Hormuz ; et une quatrième (D) correspondant à l'essor des ports d'Aden, Qalhāt (Oman) et Maqdishūh (Mogadiscio) (Ibn al-Mujāwir 1951, p. 130 et 287). Ibn al-Mujāwir n'offre guère de précisions chronologiques sur ces quatre moments, et la valeur de son témoignage a parfois été remise en doute.

On peut toutefois relever que cette périodisation correspond bien à ce que l'on sait par ailleurs des heurts et malheurs des ports qu'il évoque (tabl. 64). On ne s'attardera guère ici sur l'histoire de Raysūt, qui reste encore largement à explorer.
Celle de Șuhār, objet des travaux archéologiques menés sous la direction de Monique Kervran, est bien mieux connue (Kervran 2004). L'étude du site a montré qu'après un moment d'apogée au $\mathrm{x}^{\mathrm{e}}$ siècle, il connut un déclin rapide au cours $\mathrm{du}_{\mathrm{XI}}^{\mathrm{e}}$ siècle, rendu définitif par le pillage de la ville lors de la campagne seljoukide contre l'Oman en 1053 (période B). Cet effacement de Șuhār contraste effectivement avec l'affirmation d'al-Tīz et Hormuz dans la seconde moitié $\mathrm{du} \mathrm{XI} \mathrm{XI}^{\mathrm{e}}$ siècle, sous la protection des sultans seljoukides du Kirmān (période C). Cette situation se prolongea jusqu'au premier tiers du XII ${ }^{\mathrm{e}}$ siècle, avant que la puissance seljoukide ne soit démembrée par les Khwārizm-Shāh et que les deux ports ne passent dans la sphère d'influence de l'île de Qays. Qalhāt, de son côté, aurait été fondée au début du $\mathrm{XII}^{\mathrm{e}}$ siècle et s'affirme véritablement dans la première moitié du XIII ${ }^{\mathrm{e}}$ siècle (Rougeulle 2010), de même que Maqdishūh, mentionnée pour la première fois dans les sources écrites chez Ibn al-Mujāwir et Yāqūt al-Hamawī (premier tiers du $\mathrm{XIII}^{\mathrm{e}}$ siècle) (période D). Le cas d'Aden est plus délicat, car le port est déjà très actif à l'époque où al-Muqaddasī le visite à la fin $\mathrm{du} \mathrm{X}^{\mathrm{e}}$ siècle. Aden connaît une prospérité indéniable par la suite, comme l'attestent les documents de la Geniza (Margariti 2007). L'installation des Ayyoubides dans le dernier quart du $\mathrm{XII}^{\mathrm{e}}$ siècle a toutefois peut-être donné un nouvel élan aux activités du port, d'où le jugement d'Ibn al-Mujāwir (Ibn al-Mujāwir 1951, p. 130). Ces synchronismes peuvent apparaître forcés à certains égards, ils n'en permettent pas moins de distinguer plusieurs configurations

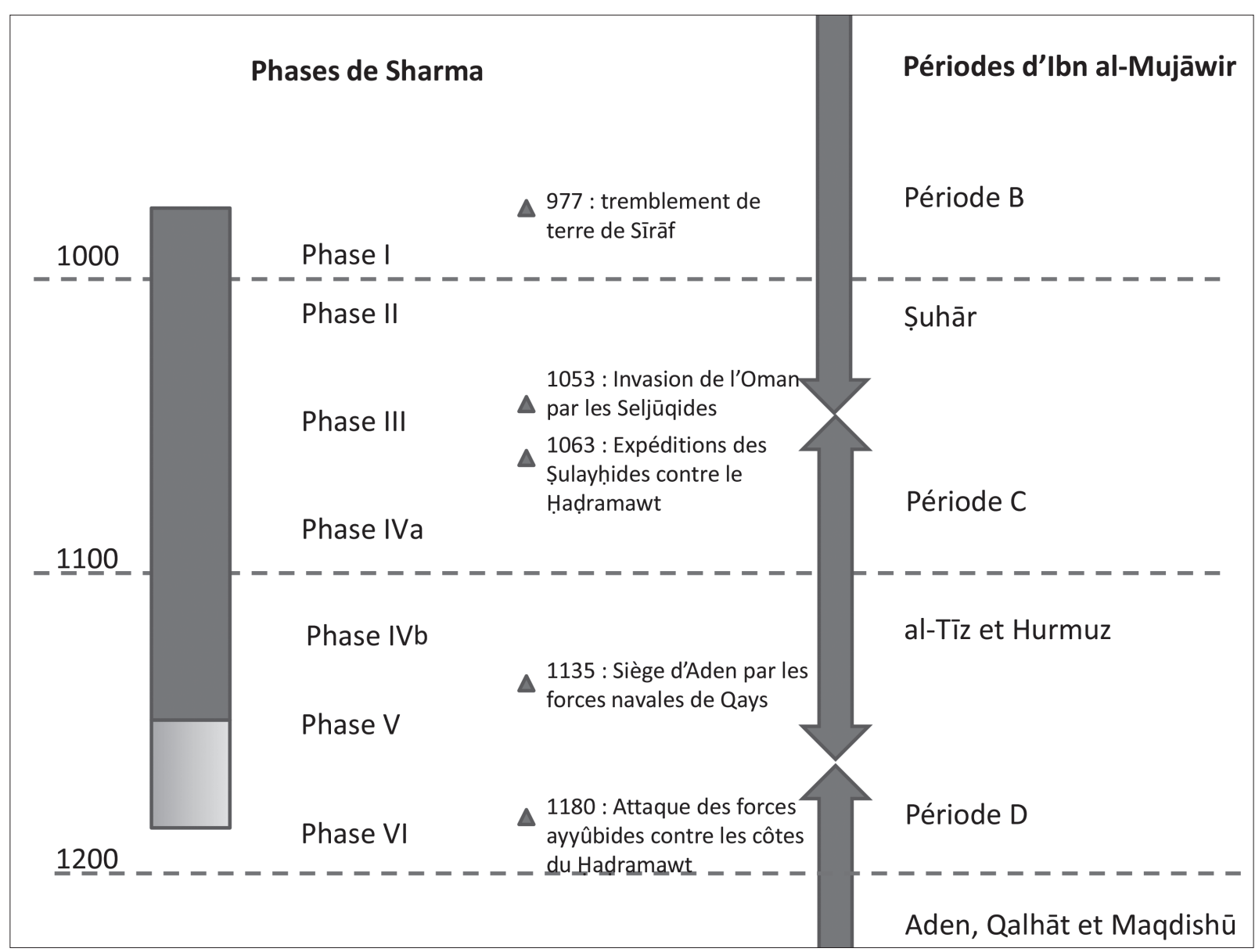

Tabl. 64 - Chronologie comparée de Sharma et de sa région. 
successives des réseaux d'échange maritime dans cette vaste zone allant du golfe d'Oman au golfe d'Aden, et même plus au sud, aux premiers rivages de la mer des Zanj.

La vie de Sharma s'étend sur les deuxième et troisième périodes distinguées par Ibn al-Mujāwir, celle qui voit le passage d'un réseau polarisé par Șuhār à un réseau polarisé par Hormuz et al-Tīz, avec un moment de rupture important au milieu du $\mathrm{XI}^{\mathrm{e}}$ siècle. Or l'étude archéologique minutieuse du site (supra, parties II et III) montre une césure importante dans l'histoire de Sharma à cette même période, qui correspond également au moment d'édification, puis de démantèlement rapide de la première enceinte (phase III de Sharma), précédant une expansion sans précédent du site avec la multiplication du nombre d'entrepôts dans la seconde moitié $\mathrm{du} \mathrm{XI}^{\mathrm{e}}$ siècle et au début du XII ${ }^{\text {e }}$ siècle (phase IV de Sharma). Il existe donc une corrélation forte entre l'évolution du site de Sharma, et la succession des deux périodes, que nous baptiseront à la suite d'Ibn al-Mujāwir, période « Șuhār » et période « Hormuz/al-Tīz ».

Toute la question est maintenant de savoir si la fonction et la place de Sharma au sein des réseaux d'échange de la mer d'Arabie étaient les mêmes au cours de ces deux périodes. Si Sharma a été fondé et a connu un premier développement, limité, au cours de la période Șuhār, c'est bien au cours de la période Hormuz/al-Tīz que ce site en est venu à assumer, quelques décennies durant, un rôle pivot essentiel dans les échanges entre Inde, Golfe, Arabie et Afrique de l'Est. Il convient donc d'examiner ces deux moments séparément.

\section{V/2-4. Sharma et les réseaux sirafis de la période Șụ̣ār (980-1050)}

Deux sources de la première moitié du $\mathrm{x}^{\mathrm{e}}$ siècle offrent une image vivante et assez détaillée de ceux qui dominaient alors le commerce maritime de l'Arabie et assuraient une grande partie des échanges entre ses rives et le reste du bassin de l'océan Indien occidental. Dans ses Prairies d'Or (Murūj al-dhahab), al-Mas' 'ūdī (m. 956) les désigne comme les «nākhūdhā (patrons de navire) de Sīrāf et d'Oman qui parcourent les mers de la Chine, de l'Inde, du Sind, de Zanjibār, du Yémen, d'al-Qulzum ${ }^{12}$ et de l'Abyssinie $^{13}$ » et mentionne les noms de certains d'entre eux. Sur les vaisseaux de Muhammad b. Zaybabūd, de Jawhar b. Aḥmad, surnommé Ibn Sīra, d'Aḥmad et 'Abd al-Șamad b. Ja'far al-Sīrāfì, il dit s'être rendu plusieurs fois dans l'île de Qanbalū, au large de la côte des Zanj. Mais c'est surtout dans le livre des Merveilles de l'Inde (Kitāb 'ajā'ib al-Hind) que l'on voit ce milieu à l'œuvre. Nombre des 134 anecdotes que recèle l'ouvrage, auquel il faut désormais ajouter plus d'une vingtaine de récits supplémentaires récemment retrouvés, sont rapportées

\footnotetext{
${ }^{12}$ Clysma. Ce nom désigne couramment la mer Rouge dans la géographie arabe.

${ }^{13}$ Al-Mas'ūdī 1962, p. 105 § 305. Voir aussi p. 84 § 216; p. 94 § 246 ; p. $137, \S 367$; p. $140 \S 380$
}

par des navigateurs portant le nom d'al-Sīrāfì, et nombre d'entre elles les mettent en scène ${ }^{14}$.

Șuhār apparaît bien à cette époque comme le nœud principal des échanges développés par ce réseau. C'est de Șuhār qu'al-Mas'ūdī partit pour gagner Qanbalū et c'est également le port de 'Umān qui est le plus cité dans les Merveilles de l'Inde $e^{15}$. Le littoral de l'Arabie du Sud n'apparaît que très épisodiquement, comme une étape ou un relais commode depuis l'Inde du Sud en direction de la côte omanaise. Deux récits montrent notamment des navires voguant de pleine mer depuis l'Asie du Sud-Est jusqu'à la côte du «Shiḥr » (appelé ici Shiḥr de l'encens) qui correspond aussi bien au Dhofar actuel qu'à la région côtière de la ville qui porte aujourd'hui ce nom. Le récit d'une traversée de Muḥammad b. Bābishād depuis Fanșūr vers l'Oman mentionne ainsi un itinéraire de pleine mer débouchant à Raysūt (Dhofar actuel). L'anecdote souligne le désaccord entre le pilote et le patron du navire sur le lieu exact de leur arrivée, ce qui prouve que c'était plus la côte elle-même qui était recherchée (« la rive des Arabes » selon l'expression même du texte) qu'un port en particu$\operatorname{lier}^{16}$. Le passage par ce même littoral du Haḍramawt et du Dhofar était aussi nécessaire pour qui souhaitait contourner l'Arabie afin de se rendre du Golfe en mer Rouge, mais les anecdotes du Livre des merveilles évoquent à ce propos la dangerosité des parages du Shị̣r, en raison des coups de vent fréquents, plutôt que les escales qui étaient sans doute pratiquées au cours de ce cabotage, mais sur lesquelles on ne saura rien ${ }^{17}$. On retient à cette lecture l'impression de rivages qui n'étaient guère recherchés pour eux-mêmes et d'une façade maritime plutôt sauvage, où l'on ne débarquait qu'au gré des hasards de la navigation. Cela ne signifie pas qu'ils étaient entièrement ignorés - la région était réputée pour son encens et ses poissons, et certains ports comme al-As' ${ }^{\natural} \bar{a}$ '/al-Shiḥr ou Hayrīj témoignent d'activités marchandes -, mais il ressort de cela qu'ils ne jouaient qu'un rôle très secondaire dans l'organisation des réseaux de navigation.

La création d'un site tel que Sharma, même s'il ne comptait au départ qu'un petit nombre de magasins, correspond de ce fait à une évolution notable. Elle suppose la circulation régulière de navires, passant par ce secteur de la côte et souhaitant s'y arrêter pour y déposer et y entreposer leurs cargaisons, comme si, à compter de cette période, la côte de l'Arabie du Sud était appelée à jouer un rôle plus systématique dans les échanges maritimes de la partie nord de l'océan Indien occidental. Cette fondation prend d'autant plus de relief qu'elle n'est pas isolée : d'autres comptoirs créés à partir du début du $\mathrm{X}^{\mathrm{e}}$ siècle sont aussi attestés, comme al-Hamr al-Sharqiyya (Dhofar actuel), dont l'organisation, à une échelle beaucoup plus réduite, n'est pas sans rappeler celle de Sharma (Rougeulle 2007b).

\footnotetext{
${ }^{14}$ Voir Van der Lith \& Devic 1883-1886 ; Sauvaget 1954 ; al-Sīrāfī 2006 ; Ducène 2010.

${ }^{15}$ Van der Lith \& Devic 1883-1886, index p. 221, s. v. 'Umān.

${ }^{16}$ Ibid., p. 90 § XLVI. Voir également pour un parcours similaire LXXXI,

p. $129-130$.

${ }^{17}$ Ibid., p. 147 § XCIII.
} 
On ne dispose malheureusement d'aucun texte comparable aux Merveilles de l'Inde après le $\mathrm{x}^{\mathrm{e}}$ siècle, et les mentions précises d'armateurs de Sīrāf et d'Oman, qui permettraient de suivre l'évolution de leurs itinéraires et le déploiement de leurs activités marchandes, notamment dans la première moitié $\mathrm{du} \mathrm{XI}^{\mathrm{e}}$ siècle, sont rares. Le grand géographe al-Muqaddasī (m. apr. 990) confirme toutefois que la population marchande d'Aden et de Jeddah était composée de Persans arabisés à la fin du $\mathrm{x}^{\mathrm{e}}$ siècle (al-Muqaddasī 1906, p. 79), et l'on se souvient qu'Ibn al-Mujāwir place également à la fin du $\mathrm{x}^{\mathrm{e}}$ siècle le moment de la grande dispersion des Sirafis autour de la péninsule Arabique. On a souvent incriminé ce mouvement aux tremblements de terre qui auraient touché Sīrāf en 366 et 367/976-978 ${ }^{18}$, mais la lecture attentive du témoignage contemporain que livre al-Muqaddasī montre bien que ce redéploiement des réseaux marchands avait déjà été entamé auparavant, avec l'arrivée au pouvoir des Bouyides en Iran et en Iraq qui suscita d'importants mouvements militaires dans le Golfe dès le milieu du IX ${ }^{\mathrm{e}}$ siècle (al-Muqaddasī 1906, p. 426).

L'instabilité du pouvoir des émirs wājihides en Oman et la menace carmate entraînèrent en 352/962 une première expédition bouyide dans cette région destinée à rétablir l'ordre, puis dès 356/967 l'établissement d'un gouvernement direct des Bouyides sur la côte omanaise (Piacentini 2005). Les expéditions partirent de Sīrāf et mobilisèrent sans aucun doute des navires marchands. Selon al-Muqaddasī, c'est à cette occasion que les habitants de Sīrāf se déplacèrent vers Șuhār et « peuplèrent la capitale de l'Oman ». Outre al-Muqaddasī, la description contemporaine de l'auteur anonyme des Hudūd al-'ālam (372/982) témoigne de l'insolente prospérité de la cité à cette période, qui devait perdurer encore jusqu'au milieu

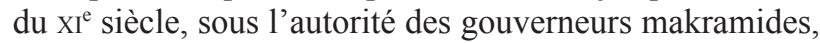
régnant sur l'Oman au nom des Bouyides. L'extension de l'autorité bouyide à l'ensemble des rives du Golfe et de la mer d'Oman favorisa au cours de la même période le développement des échanges entre les ports du Makrān, Hormuz et al-Tīz, et les ports omanais, comme l'atteste la diffusion des premiers sgraffiatos, céramique probablement venue de l'Iran du Sud-Est. L'extension de l'autorité bouyide ne semble pas en revanche, être allée au-delà du golfe d'Oman. Les différentes expéditions maritimes montées depuis la côte iranienne entre le milieu du $\mathrm{x}^{\mathrm{e}}$ et le milieu du $\mathrm{XI}^{\mathrm{e}}$ siècle n'eurent pas d'autre visée que la côte omanaise. En aucune manière les forces navales agissant au nom des Bouyides ne semblent être allées plus loin, vers la côte du Shihr, que les Bouyides n'eurent jamais la prétention de faire passer sous leur autorité. La fondation de Sharma ne peut donc être directement rattachée à ce mouvement d'expansion militaire, même si la stabilité politique relative qui régna dans le Golfe jusqu'au milieu $\mathrm{du} \mathrm{XI}{ }^{\mathrm{e}}$ siècle favorisa sans nul doute le commerce maritime à partir de cette région.

Le contexte global du commerce avec l'Extrême-Orient était de fait assez favorable. L'établissement des Song en Chine

\footnotetext{
${ }^{18}$ Al-Muqaddasī indique qu'il y eut des tremblements de terre au cours des deux années. On retient d'ordinaire la date de 977.
}

à partir de 960 correspond à un nouveau cycle de prospérité : le commerce connut un essor rapide dans l'empire réunifié et les échanges maritimes s'intensifièrent, passant notamment par le grand port de Quanzhou (Beaujard 2012, II, p. 160-169 ; Schottenhamer 2000). L'économie chinoise joua un rôle d'entraînement sur celle de l'Asie du Sud-Est et les connexions avec l'Inde du Sud et Sri Lanka étaient également denses (Wade 2009, p. 221-265). Sur la côte occidentale de l'Inde, la période 980-1050 semble aussi correspondre à une période d'essor du commerce maritime : les Cholas étendent leur hégémonie sur un vaste espace allant de Sri Lanka aux Maldives, peut-être au service d'une active politique commerciale maritime (Thapar 2004, p. 365). Aucune des régions de la côte indienne ne paraît échapper à ce mouvement d'intensification des échanges par voie de $\operatorname{mer}^{19}$. La forte présence de céramique indienne à Sharma n'a donc rien d'étonnant de ce point de vue.

On doit également souligner que l'apparition et le développement de Sharma sont aussi concomittants d'importantes mutations sur la côte d'Afrique de l'Est, que les géographes arabes désignaient sous le nom de Bilād al-Zanj. Les fouilles menées en divers lieux, depuis les îles de Pemba et Zanzibar jusqu'à Madagascar, montrent l'apparition au cours de la seconde moitié du $\mathrm{x}^{\mathrm{e}}$ siècle de véritables petites villes islamiques, à partir de sites plus modestes préexistants ou de fondation ex nihilo, comme à Mtambwe Mkuu et Ras Mkumbu (Pemba), Kilwa ou Sanjé ya Kati (Horton, à paraître ; Pradines 2009). La diffusion de frappes monétaires locales montre également l'enracinement de nouveaux pouvoirs locaux islamiques. L'exemple le plus fameux est celui des pièces frappées au nom d'al-Hasan b. 'Alī, un personnage identifié avec le fondateur de la première dynastie de Kilwa, selon ce que rapportent les Chroniques de Kilwa, et dont le règne se situe à un moment qui n'est pas encore connu avec précision entre la fin du $\mathrm{X}^{\mathrm{e}}$ et le milieu du XI ${ }^{\mathrm{e}}$ siècle (Horton et al. 1986). Même si cela reste difficile à prouver, cet essor urbain général suppose un développement des échanges commerciaux, au sein de l'espace est-africain lui-même, et avec les régions plus lointaines de l'océan Indien. Même si la présence de marchands musulmans est attestée bien avant cette période, sans doute dès les premiers temps de l'Islam, l'urbanisation et l'islamisation de cette longue bande littorale connaissent ainsi un seuil décisif dans la seconde moitié du $\mathrm{X}^{\mathrm{e}}$ siècle. On peut saisir un peu de l'engouement renouvelé pour le commerce avec les Zanj chez al-Muqaddasī : arrivé à Aden dans les années 980, c'est vers ce négoce qu'il s'oriente - plus que vers celui en direction du Golfe, de l'Inde et de la Chine (al-Muqaddasī 1906, p. 97).

La céramique locale africaine, présente en très grande quantité à Sharma dès la première phase, manifeste de troublantes similitudes avec celle du site contemporain de Mtambwe Mkuu (Horton, à paraître ; Fleisher et alii 2015) et l'importance de cette « connexion africaine » de Sharma suggère que sa fondation et son premier développement eurent beaucoup à voir avec l'apparition de

\footnotetext{
${ }^{19}$ Chakravarti 1998 ; voir plus largement à ce sujet le chapitre de synthèse d'E. Lambourn dans Rougeulle et Vallet, à paraître.
} 
ce nouveau paysage urbain et mercantile en Afrique de l'Est. L'établissement de relations plus régulières avec le Golfe, rendues possibles par l'apparition d'un relais stable comme Sharma, accompagna sans nul doute ce « boom » urbain est-africain. Par rapport à d'autres mouillages de la côte sudarabique, comme Raysūt, la fondation d'une plaque-tournante aussi occidentale que Sharma présentait un intérêt certain pour la circulation en direction du pays des Zanj : Sharma était l'un des points de la côte arabique les plus proches à vol d'oiseau du Cap Gardafui et du Ra's Hafun. À la fin du Xve siècle, le seul itinéraire partant de Sharma mentionné par le navigateur Ibn Mājid dans ses fameux Fondements de la science nautique (Fawā'id fì 'ilm al-bahr) conduit justement à ce dernier cap (cité par Serjeant 1963, p. 110). Pour Sharma, la route africaine était donc en quelque sorte la « voie royale».

Si peu de traces des produits de luxe - or et ivoire - ordinairement associés au Bilād al-Zanj ont été retrouvées à Sharma, les fouilles ont toutefois révélé l'importance de la circulation du copal et la présence d'une abondante céramique domestique africaine utilisée sur place. Est-elle la trace du passage éphémère de cohortes d'esclaves qu'il fallait bien nourrir en attendant que les vents favorables permettent aux navires de regagner le Golfe ? L'hypothèse ne peut être exclue. La traite des esclaves a laissé peu de traces matérielles, et son archéologie reste encore largement à découvrir dans l'espace indo-océanique. L'importation d'esclaves depuis le Bilād al-Zanj vers le monde islamique à l'époque de Sharma n'a pas fait l'objet d'études précises, même si des mentions éparses attestent la continuité de cette traite en direction du Yémen et du Golfe $^{20}$. Une partie des tombes de l'important cimetière qui se trouve à l'est du site, comprenant des sépultures d'hommes, de femmes et d'enfants correspondraient-elles à des dépouilles d'esclaves morts en transit ? Cela ne peut être prouvé.

Il est toutefois certain que la fondation de Sharma ne prend tout son sens que dans le cadre de circuits de navigation reliant plus étroitement la côte indienne et la côte de l'Afrique de l'Est. L'alternance des vents dans l'océan Indien, avec la domination des vents du sud-ouest au moment de la mousson, et des vents d'est entre octobre et mars, faisait de la côte du Haḍramawt et du Dhofar un point de passage quasi-obligé pour qui souhaitait passer d'une côte à l'autre. Les navires du sud du subcontinent indien pouvaient gagner la côte arabique et Sharma au printemps, et y déposer leurs riches cargaisons de porcelaine chinoise et d'autres produits exotiques, à même d'être ensuite rechargés vers le Golfe, la mer Rouge ou le Bilād al-Zanj lorsque les saisons de navigation le permettaient. Plus encore, la présence du cap permettait aux navires venus de l'ouest (Yémen ou Afrique de l'Est) d'être à l'abri durant la saison des vents d'est (azyab), particulièrement redoutée dans ce secteur. La venue des navires à Sharma obéissait à de fortes contraintes saisonnières, et il

\footnotetext{
${ }^{20}$ Voir dans la Geniza, la mention de l'achat d'esclaves arrivées sur un navire depuis le Bilād al-Zanj vers 1140 : Goitein \& Friedman 2008, p. $453-454,456$.
}

est clair que l'activité de l'entrepôt devait être soumise à de fortes fluctuations dans l'année, ce qui pourrait expliquer aussi pourquoi une vie urbaine permanente ne s'y est pas développée.

Doit-on voir dans la mise en place de ce système « triangulaire » Inde-Arabie-Afrique autour de Sharma la main des Sirafis ? Aucune preuve formelle ne le confirme mais les marchands du Golfe, adossés aux ports de Sīrāf et plus encore de Șuhār à la fin du $\mathrm{x}^{\mathrm{e}}$ siècle apparaissent comme les seuls capables de mettre en place et d'entretenir sur la durée un tel réseau. Outre leur capacité bien attestée à fonder des établissements côtiers (Ibn al-Mujāwir), on peut noter qu'ils disposaient également à la fin du $\mathrm{X}^{\mathrm{e}}$ siècle d'une forte autonomie, $\mathrm{y}$ compris militaire, comme le rappelle al-Muqaddasī : dans les mers d'Arabie, entre Aden et l'Oman, « aucun navire ne peut se passer d'hommes en armes (muqātila) et d'artificiers (naffātūn) » (al-Muqaddasī 1906, p. 12). Les menaces survenaient principalement en mer, sous les traits des pirates indiens notamment, mais la présence d'une force à bord comptait aussi certainement lorsque le maître du navire négociait de pouvoir mouiller et s'approvisionner au large d'un territoire sous domination tribale. Une négociation entre chefs de tribus et marchands armés, c'est ainsi, sans doute, que naquit Sharma.

\section{$\mathrm{V} / 2-5$. Sharma et les réseaux sirafis de la période Hormuz/al-Tīz (1050-1135)}

Le milieu du $\mathrm{XI}^{\mathrm{e}}$ siècle voit deux bouleversements politiques majeurs se produire dans la région de la mer Rouge et dans celle du Golfe. D'une part, le pouvoir bouyide, déjà significativement affaibli, s'effondre face à celui des Turcs Seldjoukides. Dès 1041 s'établit une branche seldjoukide dans la région du Kirmān, à l'ombre de laquelle les ports de Hormuz et d'al-Tīz connurent une prospérité nouvelle. La conquête du Fārs s'avéra plus difficile et les Seldjoukides eurent beaucoup de mal à y rétablir l'ordre, notamment face à l'agitation des tribus Shabankara qui rendirent impraticables les routes desservant Sīrāf jusqu'aux années 1130 (Aubin 1959, p. 297). Șuhār, déjà affaiblie par des luttes intestines dans le deuxième quart $\mathrm{du} \mathrm{XI}^{\mathrm{e}}$ siècle, ne se remit jamais des pillages survenus lors de l'invasion seldjoukide en 1053 et ses activités commerciales cessèrent presque totalement à compter de cette période. Aucun témoignage direct ne nous est parvenu de la réaction des marchands et des armateurs du Golfe à ces bouleversements rapides, mais il est certain que l'effondrement, au moins temporaire, du commerce omanais entraîna une nouvelle configuration des réseaux de navigation dans cette région. L'augmentation spectaculaire du nombre d'entrepôts à Sharma n'est pas le seul signe de cette réorientation vers l'Arabie du Sud d'une partie du trafic qui se dirigeait auparavant vers l'Oman. On note aussi à partir de la seconde moitié du XI ${ }^{\mathrm{e}}$ siècle l'essor du port de Mirbāt, sur la côte du Dhofar, où s'établit une lignée d'origine persane, les Manjawī, ainsi que du port de Zafār.

Cette nouvelle géographie marchande apparaît clairement dans les sources de la Geniza datées de la fin 
$\mathrm{du} \mathrm{XI}^{\mathrm{e}}$ siècle. Dans une lettre datée des années 10941096/1097, un marchand juif d'Alexandrie donne des nouvelles de son beau-frère qui, arrivé depuis l'Inde à Mirbāt, avait l'intention de se rendre directement dans le port égyptien d' "Aydhāb, sans passer par Aden (Goitein \& Friedman 2008, p. 295). Une autre lettre, rédigée vraisemblablement en 1098, rapporte le trajet d'un autre marchand juif, Joseph al-Lebdi, depuis Aden vers al-Tīz, puis son retour en passant par Mirbāṭ où il dut séjourner quelques temps (Goitein \& Friedman 2008, p. 205-206). Sharma n'apparaît pas dans cette documentation, où, de façon plus générale, les marchands juifs ne paraissent guère intéressés par le commerce avec le Bilād al-Zanj, mais plutôt tournés vers l'Inde. L'apparition timide de céramique venue de la mer Rouge à Sharma témoigne toutefois à sa façon de cette nouvelle configuration.

À l'ouest, l'avènement des Sulayhides (1047-1138), une nouvelle dynastie fidèle aux califes fatimides d'Égypte, entraîna également un bouleversement. Pour la première fois depuis longtemps, un pouvoir d'origine tribale, parti du nord du Yémen (région du Haraz, à l'ouest de Sanaa), parvenait à s'emparer du Bas-Yémen jusqu'au port d'Aden. En 1063, 'Alī al-Ṣulayḥ̄î, premier souverain de la dynastie, aurait même lancé une offensive contre le Haḍramawt, selon des sources qui restent difficiles à vérifier. Ces troupes défirent les Ibadites de l'intérieur du wadi, mais ne dominèrent pas longtemps le Haḍramawt ${ }^{21}$. Elles furent notamment combattues par l'imam ibadite Ibrāhīm b. Isḥāq al-Hamdānī al-Haḍramī (al-Shātirī 1972, p. 147). 'Alī b. Muḥammad al-Ṣulayḥ̄ se serait un temps emparé de la ville d'al-As'ā', rattachée à l'autorité des Banū Ma'an, gouverneurs d'Aden (al-Shātịī 1972, p. 147). La première muraille construite brièvement à Sharma vers le milieu du $\mathrm{XI}^{\mathrm{e}}$ siècle (phase III) serait-elle une réponse à cette offensive șulayhide venant par voie de terre depuis al-As`āa/al-Shiḥr ? C’est une hypothèse à ne pas négliger.

Au-delà de la seule histoire de Sharma, certains historiens hadramis contemporains n'hésitent pas à voir dans cette intervention șulayhide le facteur déclenchant d'un durcissement des conflits tribaux sur la côte du Shị̣r et à l'intérieur même du Haḍramawt. Pour l'historien hadrami Șālih al-Hāmid, l'installation du nouveau clan tribal des $\bar{A}$ l Iqbāl dans la ville d'al-As‘ā/al-Shiḥr serait le résultat du soutien initial que le pouvoir șulayhide leur aurait apporté. La région, devenue plus riche, plus active, devint convoitée par des États plus lointains, comme celui des Șulayhides du Yémen et même, si l'on en croit un récit d'Ibn al-Athīr, par des aventuriers turcs de la mouvance des Seldjoukides à la fin du $\mathrm{XI}^{\mathrm{e}}$ siècle. Ces pressions plus fortes exercées par les puissances solidement établies au Yémen ou dans l'espace irako-iranien rendaient sans doute plus difficile à maintenir un comptoir comme Sharma, reposant sur l'entente entre tribus locales et marchands autonomes. L'avenir était désormais aux cités-États comme Aden ou Mirbāt, bien défendues par leurs enceintes et capables de

\footnotetext{
21 al-Hāmid 1968, p. 405, s'appuyant sur la chronique ancienne de Bā Hasan, dont aucun manuscrit n'est malheureusement accessible actuellement.
}

s'appuyer sur une force militaire conséquente. La concurrence et la militarisation accrue du commerce maritime au $\mathrm{XII}^{\mathrm{e}}$ siècle, dont témoigne l'expédition de la flotte de Qays en 1135 contre Aden, constitue sans doute la toile de fond du déclin rapide de Sharma.

\section{V/2-6. Le temps des cités-États et la fin de Sharma}

En 1135, huit navires du maître de Qays, petite île située dans le fond du golfe Arabo-Persique, non loin de Sīrāf, établissaient, au terme d'un voyage maritime de plusieurs milliers de kilomètres, un blocus maritime de la ville d'Aden, dans l'espoir de la soumettre à la suzeraineté qaysite. L'expédition se solda par un échec et la cité d'Aden continua de prospérer sous l'autorité de ses propres princes, les Zuray'ides, jusqu'au dernier quart du XII ${ }^{\mathrm{e}}$ siècle (Goitein 1954 ; Margariti 2007). Cet épisode constitue à bien des égards une rupture, à la fois par l'ampleur de l'expédition ainsi organisée et la distance parcourue, mais aussi par le fait qu'il opposait, pour la première fois, deux cités-États islamiques des pourtours de l'océan Indien; et enfin, par l'impact qu'il eut sur les réseaux sirafis.

On ne peut qu'être frappé par la coïncidence entre cette expédition et les dates présumées du déclin de Sharma. Le coup d'éclat naval de Qays contre Aden, même s'il se solda par un échec, était en réalité l'aboutissement d'un processus rapide qui vit les réseaux du Golfe se recomposer autour d'un pouvoir nouveau, une dynastie locale adossée à une cité marchande insulaire. Quelques indices dispersés dans les sources permettent de reconstituer les principales étapes de l'ascension de Qays. Les premières traces d'un pouvoir autonome dans l'île datent du milieu $\mathrm{du} \mathrm{XI} \mathrm{I}^{\mathrm{e}}$ siècle dans le contexte troublé de l'avènement des Seldjoukides, mais il faut attendre la fin $\mathrm{du} \mathrm{XI}^{\mathrm{e}}$ siècle pour voir un prince de Qays, Abū al-Qāsim, mettre la main sur le port de Sīrāf (Ibn al-Balkhī) et prélever des droits sur tous les navires empruntant la route maritime qui longeait la côte iranienne. Profitant de l'affaiblissement des Seldjoukides du Kirmān à partir des années 1130, Qays étendit progressivement son hégémonie à certains autres ports du Golfe, de l'Oman, du Sind et du Gujarat, jusqu'à tenter de soumettre le port d'Aden. Ici s'affirmait une politique de vaste ampleur visant à faire passer les principales voies du grand commerce maritime dans l'océan Indien occidental sous l'autorité d'une cité-État portuaire islamique, non sans succès puisque " l'empire » maritime de Qays subsista jusqu'au début du XIv ${ }^{\mathrm{e}}$ siècle, avant d'être supplanté par celui d'Hormuz (Piacentini 1999 et 2004).

Cette politique allait sans doute à l'encontre des intérêts des grands négociants et armateurs établis depuis le milieu du $\mathrm{XI}^{\mathrm{e}}$ siècle entre al-Tīz, Hormuz et Aden. On en tient la preuve avec le personnage de Rāmisht le Sīrāfì, puissant marchand dont les affaires étaient menées de la Chine au Bilād al-Zanj par un réseau familial composé de ses fils et de quatre esclaves (voir Ibn Hawqal 1964, p. 277-278; Stern 1967) : ce sont deux navires armés lui appartenant qui sauvèrent en 1135 Aden des navires de Qays. Mais si le principal port du Yémen échappa aux vélléités expansion- 
nistes du prince qaysite, il n'est pas sûr que les réseaux des grands marchands du Golfe n'aient pas été durablement désorganisés par cette nouvelle donne. La fondation de nouveaux points d'ancrage sirafis en mer Rouge sur l'île de Kamarān (années 1120), comme à al-Ahwāb avec le même Rāmisht en 1137-1138 (voir supra) est peut-être le signe du repli de ces réseaux marchands sur une zone qui échappait à Qays.

Les navires de Qays s'arrêtèrent-ils à Sharma sur leur chemin depuis ou vers le Golfe ? La présence des siga égyptiennes scellant la dernière phase d'occupation intensive de Sharma semblerait renvoyer à une occupation par des forces venues de l'ouest, d'Aden ou de plus loin. Or, nous n'avons pas de traces de telles expéditions avant les dernières décennies du $\mathrm{XII}^{\mathrm{e}}$ siècle. À partir de 575/1180, le gouverneur ayyūbide d'Aden, al-Zinjabīlī, et ses successeurs lancèrent à leur tour plusieurs attaques contre al-Shiḥr et le Wādī Haḍramawt, dont la plus célèbre reste celle d'Ibn Mahdī envoyé par al-Malik al-Mas' 'ūd en 616/1220. Ces expéditions conduisirent les cavaliers turcomans (Ghuzz) jusqu'à al-Shiḥr et Tarīm, à des fins de razzia plus que de soumission durable, sans remettre en cause la situation de semi-autonomie dont jouissaient alors les maîtres d'al-Shiḥr ${ }^{22}$. En 602/1205, l'atabeg Sunqūr, régent du Yémen ayyūbide, envoya même des galères depuis Aden jusqu'à Qalhāt « pour vider la mer des brigands (luṣūss) ». Et le chroniqueur yéménite d'ajouter : " Aucun des autres Ghuzz n'avait fait cela » (Ibn Hāāim 1974, I, p. 131). Les galères d'Aden auraient-elles alors passé plusieurs mois à Sharma dans l'attente des vents favorables ? Les sources ne disent rien à ce sujet, mais quelques siècles plus tard une mésaventure de cet ordre arriva à une flotte turque qui se dirigeait vers l'Inde en 937/1529-1530, et dut s'arrêter au large

\footnotetext{
${ }^{22}$ Al-Hāmid 1968, II, p. 430-432 et 493 ; Shanbal 2003, p. 73 [traduit en français par G. Ducatez dans Hardy-Guilbert 2004, p. 112].
}

de Sharma avant de faire demi-tour à cause du vent d'est $(a z y a b)$ qui les empêchait d'aller plus loin ${ }^{23}$.

\section{V/2-7. Conclusion}

Tous les mystères de Sharma n'ont pu être levés au terme de cette enquête. Mais la confrontation des données archéologiques avec le cadre historique plus général permet de proposer plusieurs hypothèses fortes pour expliquer l'apparition du site, son développement et son dépérissement. Les contraintes saisonnières de la navigation dans l'océan Indien occidental ont constitué tout au long de la période médiévale un facteur puissant de développement des mouillages du Hadramawt et du Mahra, qui pouvaient offrir une protection aux navires durant la saison de forts vents d'est (azyab) ou du sud-ouest (mousson). L'apparition et l'essor d'un entrepôt saisonnier pour les produits venus de l'Inde et de l'Extrême-Orient, du Golfe et de l'Afrique de l'Est à Sharma peut donc se comprendre dans le contexte d'une intensification des échanges entre les différentes rives de l'océan Indien, notamment prise en charge par les réseaux sirafis entre le $\mathrm{X}^{\mathrm{e}}$ et le $\mathrm{XII}^{\mathrm{e}}$ siècle. Au cours de cette période, ces réseaux se développent de manière autonome vis-à-vis des grandes puissances de l'Islam central (Bouyides et Fatimides) et n'hésitent pas à fonder leurs propres comptoirs ou entrepôts. Le renforcement des cités-États de l'océan Indien septentrional au cours du XII ${ }^{\mathrm{e}}$ siècle (Aden, Mirbāt, Qays) conduisit à une concurrence accrue pour le contrôle des routes du grand commerce maritime, à une période où le territoire côtier du Mishqāṣ fait l'objet de nouvelles convoitises. Ces pressions internes et externes expliquent sans doute pourquoi le site était condamné dès le XII ${ }^{\mathrm{e}}$ siècle et ne fut plus utilisé que de manière très épisodique par la suite. Entre $\mathrm{X}^{\mathrm{e}}$ et $\mathrm{XII}^{\mathrm{e}}$ siècle, Sharma constitua ainsi un relais essentiel dans le déploiement de réseaux islamiques marchands entre le Golfe, l'Arabie, l'Inde et l'Afrique de l'Est.

\footnotetext{
${ }^{23}$ D'après la chronique de Bā Faqīh al-Shiḥrī, citée par Serjeant 1963, p. 55.
} 


\section{Bibliographie générale}

Allibert C. 1992. Archéologie du $8^{e}$ au $11^{e}$ siècle. Fondation pour l'étude de l'archéologie de Mayotte, dossier $\mathrm{n}^{\circ}$ 1. Paris, INALCO.

Allibert C., Argant A., Argant J. 1983. Le site de Bagamoyo (Mayotte, archipel des Comores). Etudes océan Indien 2, Documents comoriens 2 (Patrimoine archéologique et histoire culturelle). Paris, INALCO / CEROI, p. 5-40.

Allibert C., Argant A., Argant J. 1989-1990. Le site de Dembeni (Mayotte, archipel des Comores). Mission 1984. Etudes Océan Indien 11, Archéologie des Comores 1 Maore et Ngazidja. INALCO / CEROI, p. 63-172.

Amigues S. 2010. Théophraste. Recherches sur les plantes. À l'origine de la botanique. Paris, Belin.

An J. 1991. Dated Islamic Glass in China. Bulletin of the Asia Institute 5, p. 123-138.

Aubin J. 1953. Les princes d'Ormuz du XIII ${ }^{\mathrm{e}}$ au XV siècle. Journal Asiatique 241, p. 177-238.

Aubin J. 1959. La ruine de Sīrāf et les routes du golfe Persique aux $\mathrm{XI}^{\mathrm{e}}-\mathrm{XII}^{\mathrm{e}}$ siècle. Cahiers de civilisation médiévale 10-12, p. 295-301.

Avanzini A. 2002. The History of Khor Rori Area, new perspectives. In A. Avanzini (éd.), Khor Rori Report 1. Pise, Edizioni Plus, p. 13-27.

Avanzini A., Buffa V., Lombardi A., Orazi R. \& Sedov A.V. 2001. Excavations and restoration of the Complex of Khor Rori. Interim Report (october 2000-april 2001). Egitto e Vicino Oriente 24, p. 5-63.

BĀ Mațraf M. 'A. 1983. Al-shuhadā'al-sab 'a. Aden, Dār al-Hamdān̄̄.

BĀFAQі̄̈ M.A. \& RoBIn Ch. 1979. Inscriptions inédites de Yanbuq (Yémen démocratique). Raydān 2, p. 15-76.

BAKer P.L. 2000. The Glass Finds. In A. D. H. Bivar (éd.), Excavations at Ghubayra, Iran. Londres, p. 197-232.

Bamber A. 1988. The Glass. In A. Northedge, A. Bamber \& M. Roaf, Excavations at 'Ana Qal'a Island. Warminster.

BARTL K. von 1997. Medieval Ceramics Einige frühislamische Glasfunde aus Madinat al-Fär / Nordsyrien Archeologie Islamique 7, p. 7-26.

BAss G. 1984. The nature of the Serçe Limani. Journal of Glass Studies 26, p. 64-69.
Bass G., Brill R., Lledo B. \& Matthews S. 2009. The Glass of an Eleven-Century Shipwreck, Serçe Limani, vol. II. College Station, Texas A \& M University Press.

Beaujard Ph. 2012. Les mondes de l'océan Indien. Tome II. L'océan Indien, au cour des globalisations de l'ancien monde ( $7^{e}-15^{e}$ siècles). Paris, Armand Colin.

Begley V., Francis P.W. \& Mahadevan I. 1996. The Ancient Port of Arikamedu, New Excavations and Researches 1989-1992, vol. 1. Paris, EFEO.

Begley V., Francis P.W., Karashima N. \& Raman K.V. 2004. The Ancient Port of Arikamedu, New Excavations and Researches 1989-1992, vol. 2. Paris-Bangkok, EFEO.

Beijing daxue kaoguxue yanjiu zhongxing 北京大學考古 學研究中心 \& Zhedong Yue yao qingci bowuguan 浙東 越窯青瓷博物館 2013. Diecui - Zhedong Yue yao qingci bowuguan cang qingci jingpin 疊翠 一浙東越窯青瓷博 物館藏青瓷精品 [Les chefs d'œuvres du musée des grès à couverte verte des fours de Yue au Zhejiang]. Pékin, Wenwu chubanshe.

Beijing kaogudui 北京考古隊 1962. Beijing nanjiao Zhao Dejun mu 北京南郊趙徳鈞墓 [La tombe de Zhao Dejun dans la banlieue sud de Pékin]. Kaogu 1962/5, p. 246-253.

Besenval R. 1994. Le peuplement de l'ancienne Gedrosie, de la protohistoire à la période islamique : travaux archéologique récents dans le Makran pakistanais. Comptes rendus des séances de l'Académie des Inscriptions et Belles-Lettres 94/2, p. 513-535.

Boivin N. \& Fuller D. 2009. Shell middens, ships and seeds: Exploring coastal subsistence, maritime trade and dispersal of domesticates in and around the ancient Arabian peninsula. Journal of World Prehistory 22, p. 113-180.

Boucharlat R. \& Lecomte O. 1987. Fouilles de Tureng Tepe, vol. 1, Les périodes sassanides et islamiques. Paris.

Boulogne S. \& Hardy-Guilbert C. 2010. Glass bangles of al-Shīhr, Hadramawt, a corpus of new data (14th-19th centuries) for the understanding of glass bangles manufacture in Yemen. Proceedings of the Seminar for Arabian Studies 40, p.135-148.

BREton J.-F. 2001. Les villes du Yémen antique, Le pays le la reine de Saba. Dossiers d'Archéologie, n 263, p. 22-29.

Breton J.-F, Badre L., Audouin R. \& Seigne J. 1980. Le wadi Hadramawt, Prospections 1978-79. Aden. 
Breton J.-F, Darles Ch., Robin Ch., \& Swauger S. 1997. Le grand monument de Tamna (Yémen) : architecture et identification. Syria 74, p. 33-72.

Brosh N. 2003. Early Islamic Glass. In Y. Israeli, Ancient Glass in the Israel Museum. The Eliahu Dobkin Collection and other Gifts. Jérusalem, p. 325-383.

Brown R.M. (éd.) 1989. Guangdong Ceramics from Butuan and other Philippines Sites. Singapour, Oriental Ceramic Society of the Philippines / Oxford University Press.

CAPPERS R.T.J. 2006. Roman Food Prints at Berenike: Archaeobotanical Evidence of subsistence and trade in the Eastern Desert of Egypt. Los Angeles, Cotsen Institute of Archaeology, University of California Press, Monograph 55.

Cappers R.T.J., Neef R. \& Bekker, R.M. 2012. Digital Atlas of Economic Plants in Archaeology. Eelde, Barkhuis.

CARswell J. 1977, China and Islam in the Maldives Islands, Transactions of Oriental Ceramic Society, vol. 61, p. 121-198.

CARboni S. 2001. Glass from Islamic Lands. Londres, Thames \& Hudson.

Carboni S. \& Whitehouse D. 2001. Glass of the Sultans. New York, the Metropolitan Museum of Arts and Corning Museum of Glass. Catalogue d'exposition.

Cardi B. De, Kennet D. \& Stocks R.L. 1994. Five Thousand Years of Settlement at Khatt, UAE. Proceedings of the Seminar for Arabian Studies 24, p. 35-96.

Cardi B. de, VitA-Finzi C. \& Coles A. 1975. Archaeological Survey in Northern Oman, 1972, East and West 25, n ${ }^{\circ}$ 1/2, p. 9-75.

CARTER R. 2005. The pottery. In T. Insoll (dir.), The land of Enki in the Islamic era. Pearls, palms and religious identity in Bahrain. Londres-New York, Kegan Paul, p. 107-192, 401-451.

Carter R.A., Challis K., Priestman S.M.N. \& Tofighian H. 2006. The Bushehr hinterland. Results of the first season of the Iranian-British archaeological survey of Bushehr province, November-December 2004. Iran 44, p. 63-103.

Casson L. 1989. The Periplus Maris Erythraei. Princeton, Princeton University Press.

Chakravarti R. 1998. Coastal Trade and Voyages in Konkan. The Early Medieval Scenario. Indian Economic and Social History Review 35, p. 127-224.

Chakravarti R. 2000. Nakhudas and Nauvittakas: Ship-Owning Merchants in the West Coast of India (c. AD 1000-1500). Journal of the Economic and Social History of the Orient 42, p. 34-64.

Changsha yao ketizu 長沙窯課題組 1996. Changsha yao 長沙窯 [Les fours de Changsha]. Pékin, Wenwu chubanshe.

Charbonnier J. 2008. L'agriculture en Arabie du Sud avant l'Islam. Une reconstitution des paysages et des systèmes de culture antiques. Chroniques Yéménites 15, p. 1-28.
Charloux G., Dridi H., Robin Ch., Schiettecatte J., Arbach M., Baqué L., al-Basīĩ̃ S., Charbonnier J., Cuny J., Émery A., Gajda I., AL-Hāju Kh., al-Nașīrī Y. \& Niveleau M. 2009. Troisième et quatrième campagnes de la mission Qatabān à Hasî, Yémen. Semitica et Classica 2, p. 227-246.

Charpentier V. 1994. A Specialised Production at Regional Scale in Bronze Age Arabia: Shell Rings from Ra's al-Junayz Area (Sultanate of Oman). In K. Koskemienni \& A. Parpola (dir.), South Asian Archaeology. Helsinki, Suomalainen Tiedakatemia (Suomalaisen Tiedakatemian Toimituksia ser. B 271, vol. 1), p. 157-170.

Charpentier V. 2004. Trihedral points: a new facet to the "Arabian Bifacial Tradition". Proceedings of the Seminar for Arabian Studies 34, p. 53-66.

Charpentier V., Blin O. \& Tosi M. 1998. Excavations at as-Suwayh SWY-2 and the beginning of Ocean exploitation in the Ja'lan. Proceedings of the Seminar for Arabian Studies 28, p. 21-38.

Charpentier V. \& Inizan M.-L. 2002. Diagnostic evidence on fluting in the Old-World: The Neolithic projectile points of Arabia. Lithic Technology 27, p. 39-46.

Charpentier V. \& Méry S. 1997. Hameçons en nacre et limes en pierre d'Océanie et de l'océan Indien : analyse d'une tendance. Société des Océanistes 105, p. 147-156.

CHEN B. 陳柏泉 1982. Jizhou yao shaoci lishi chutan 吉 州窯燒瓷歷史初探 [Recherches sur l'histoire des fours de Jizhou]. Jiangxi lishi wenwu 江西歷史文物 1982/3, p. 25-35.

CHEN D. 陳定榮 1990. Jiangxi Jinxi Song Sun Dalang mu 江西金溪宋孫大郎墓 [La tombe de Sun le Grand des Song à Jinxi au Jiangxi]. Wenwu 1990/ 9, p. 18-21.

CHEN H. 陳信雄 1998. Penghu Song Yuan taoci 澎湖宋 元陶瓷 [La céramique des Song et des Yuan trouvée sur les sites de l'archipel de Peng-hu]. Tainan, Wenshan shuju.

CHEN J. 陳建中 1999. Dehua minyao qinghua 德化民窯青 花 [Les porcelaines bleu et blanc des fours populaires de la région de Dehua], Pékin, Wenwu chubanshe.

CHEN P. 陳鵬 et al. 1982 . Fujian Jinjiang Cizao gu yaozhi [Les vestiges des fours de Cizao à Jinjiang au Fujian], KG, 1982/5, p. 490-498 et 489.

CHEN P. 陳鵬 1986. Fujian Jinjiang Cizao gu yaozhi 福 建晉江磁灶古窒址 [Les vestiges des fours de Cizao à Jinjiang au Fujian]. Kaogu 1986/10, p. 894-915.

CHEN Y. 陳衍麟 1995. Fanchang yao qi youse ji zaoxing gongyi” 繁昌窯器婇色及造型工藝 [La couverte, le décor et la forme de la céramique des fours de Fanchang]. Wenwu yanjiu 文物研究 vol. 10, p. 71-80.

Chittick H.N. 1967. Discoveries in the Lamu archipelago. Azania 2, p. 37-67.

ChitTick H.N. 1974. Kilwa an Islamic trading city on the East African Coast. Nairobi, British Institute in Eastern Africa, memoir 5, 2 vol.

CHiтtick H.N. 1984. Manda. Excavations at an island port on the Kenya coast. Nairobi, British Institute in Eastern Africa, memoir 9. 
Christie's Amsterdam 1995. The Diana Cargo, Chinese export porcelain and marine artefacts, Amsterdam, Christie's Amsterdam.

Ciuk Ch. \& Keall E. 1996. Zabid project pottery manual 1995. Pre-Islamic and Islamic ceramics from the Zabid area, North Yemen. BAR International Series 655. Oxford, Archaeopress.

Cixi shi bowuguan 慈溪博物館 et al. 2002. Shanglinhu Yue yao 上林湖越窯 [Le site de Shanglinhu du groupe des fours de Yue]. Pékin, Kexue chubanshe.

Collinet A. 2010. Au prisme de la céramique : le Sind et l'Islam. Culture matérielle du sud du Pakistan, II ${ }^{e}-X I I^{e} / V_{I I I}{ }^{e}-X V I I I^{e}$ siècles. Thèse de doctorat sous la direction de A. Northedge, Université de Paris I Panthéon-Sorbonne, Paris, n.p.

Cordemoy H.J. 1911. Les plantes à gomme et à résine. Paris, Octave Doin et Fils, éditeurs.

Costantini L. 1990. Ecology and Farming of the Protohistoric Communities in the Central Yemeni Highlands. In A. de Maigret (éd.), The Bronze Age Culture of Hawlān at-Tiyāl and al-Hadā, A First General Report. Rome, Reports and Memoirs 24, IsMEO, p. 187-204.

CRASSARD R. 2008. La préhistoire du Yémen, diffusions et diversités locales, à travers l'étude d'industries lithiques du Hadramawt. BAR International Series 1842. Oxford, Archaeopress.

Crassard R., Guy H., Schiettecatte J. \& Hitgen H. 2010. Reuse of tombs or cultural continuity? The case of towertombs in Shabwa governorate (Yemen). In L. Weeks (éd.), Death and Burial in Arabia and Beyond. Multidisciplinary perspectives. BAR International Series 2107, Society for Arabian Studies Monographs 10. Oxford, Archaeopress, p. 173-177.

Crassard R., McCorriston J., Oches E., bin 'AqIL A., Espagne J. \& Sinnah M. 2006. Manayzah, early to mid-Holocene occupations in Wâdî Sanâ. Proceedings of the Seminar for Arabian Studies 36, p. 151-173.

Cullen C.L. 2009. Perfume Flasks. In Bass et al. 2009, chapitre 19, p. 236-241.

Cullen C.L. \& Lledó B. 2009. Dish-Rim bottles. In Bass et al. 2009, chapitre 16, p. 190-213.

Cunningham A., West P.R., Hammond G.S. \& Langenheim J.H. 1977. The existence and photochemical initiation of free radicals in Hymenaea trunk resins. Phytochemistry 16, p. 1442-1443.

D’Ercole M.C. 2008. Ambres graves du département des Monnaies, Médailles et Antiques. Paris, Bibliothèque Nationale de France.

De Maigret A. 1996. New evidence from the Yemenite 'turret graves' for the problem of the emergence of the South Arabian states. In J. Reade (éd.), The Indian Ocean in Antiquity. Londres, Routledge, p. 321-337.

De Maigret A 2005. Some Reflections on the SouthArabian Bayt. In Deutsches Archäologisches Institut Șan'ā' (éd.), $A B A D Y$ X. Mayence, Verlag Philipp Zabern, p. 101-110.
De Maigret A. \& Robin Ch. 2006. Tamna', antica capitale di Qatabān / Tamna', capitale antique de Qatabān. YICAR Papers 3. Naples, Il Torcoliere.

Deane A. \& Bass G. 2009. Cuppings Glass and Alembics. In Bass et al. 2009, chapitre 34, p. 376-384.

Devaraj D.V., Narasimha Murthy A.V. \& Krishna Murthy M.S. 1993. Excavations at Talakad, 1992-1993, vol. 1. Mysore, Directorate of Archaeology and Museums in Karnataka.

AL-DIMASHQ̄i 1874. Nukhbat al-Dahr fi 'ajāi ib al-barr wa-l-baḥr. F. Mehren (trad.), Manuel de la Cosmographie du Moyen Age. Copenhague.

Duunana A. \& McKinnon E.E. 2005. The Jepara Wreck. In Pei-kai Cheng (éd.), Proceeding of the International Conference: Chinese Ceramics and Maritime Trade, 12th-15th Centuries. Hong-Kong, Chunghwa Book, p. 126-142.

Doe D.B. 1962. Notes on pottery found in the vicinity of Aden. Department of Antiquities, annual report 1960/61. Aden.

Doe D.B. 1963. Pottery sites near Aden. Journal of the Royal Asiatic Society 3-4, p. 150-162.

Doe D.B. 1971. Southern Arabia. Londres, Thames \& Hudson.

DRIDI H. 2006. Rapport préliminaire sur les deux premières campagnes de fouilles sur le site de Hașī (al-Bayḍă’, Yémen). Arabia 3 (2005-2006), p. 11-16.

DuCÈnE J.-Ch. 2010. Compte-rendu d'al-Sīrāfī, Al-șah̄inh min akhbār al-bihārr. Journal Asiatique 298/2, p. 573-605.

Dupoizat M-F 2003. Céramique chinoise. In C. Guillot (dir.), Histoire de Barus. Le site de Lobu Tua II. Étude archéologique et Document. Cahiers d'Archipel 30. Paris, p.103-169.

Ebel K.A. 2009. Cylindrical Jars. In Bass et al. 2009, chapitre 28, p. 320-334.

Evershed R.P., van Bergen P.F., Peakman T.M., LeighFirbank E.C., Horton M.C., Edwards D., Biddle M., Jjolbye-Biddle B. \& Rowley-Conwy P.A. 1997. Archaeological frankincense. Nature 390, p. 667-668.

FehÉRvari G. 2000. Ceramics of the Islamic world in the Tareq Rajab Museum. Londres, New York, I.B. Tauris Publishers.

FERRAND G. 1922, Voyage du marchand arabe Sulayman en Inde et en Chine, rédigé en 851 suivi de remarques par Abû Zayd Hasan (vers 916). Paris, éd. Bossard.

FleCKer M. 1999. Three $18^{\text {th }}$-Century Shipwrecks off Ujung Pandang, Southwest Sulawesi, Indonesia: A Coincidence? The International Journal of Nautical Archaeology 28, p. 45-59.

FLEISHER J. 2010. Rituals of Consumption and the Politics of Feasting on the Eastern African Coast, AD 700-1500. Journal of World Prehistory 23/4, p. 195-217. 
Fleisher J. \& Wynne-Jones S. 2010. Kilwa-type coins from Songo Mnara, Tanzania: New Finds and Chronological Implications. Numismatic Chronicle 170, p. 494-506.

Fleisher J., Lane P., LaViolette A., Horton M., Pollard E., Quintana Morales E., Vernet T., Christie A., \& Wynne-Jones S. 2015. When Did the Swahili Become Maritime? American Anthropologist 117(1). [en ligne] http://onlinelibrary.wiley.com/doi/10.1111/aman.12171/full

Flood F.B. 2009. Objects of Translation. Material Culture and Medieval "Hindu-Muslim " Encounter. Princeton, Princeton University Press.

Foshan shi bowuguan 佛山市博物館 1978. Guangdong Shiwan yaozhi diaocha” 廣東石灣窯址調查 [Prospections du site de Shiwan au Guangdong]. Kaogu 1978/3, p. 195-199.

Foy D. 2011. L'atelier de verrier de Sabra al-Mansuriya : une production diversifiée du XI ${ }^{\mathrm{e}}$ siècle. In N. Hentati (éd.), Contributions scientifiques et apports techniques de Kairouan, colloque international du Centre d'Etudes islamiques de Kairouan, 24-25 avril 2009. Tunis, p. 359-383.

Foy D. (à paraître). Les verres de Sabra al-Mansûriya. Productions locales et importations. In P. Cressier \& M. Rammah (éds), Sabra al-Mansûriya. Capitale fatimide. Ecole Française de Rome.

Francis P. 2002. Asia's maritime bead trade from ca. 300 $B C$ to the Present. Honolulu, University of Hawai'i Press.

FRIFELT K. 2001. Islamic remains in Bahrain. Jutland Archaeological Society publications 37. Højbjerg.

Fuller D.Q. 2003. Further evidence on the prehistory of sesame. Asian Agri-History 7-2, p. 127-137.

Fuller D.Q. 2006. A Millet Atlas: Some Identification Guidance. MG101: Archaeobotany in Practice, Institute in Archaeology, University College London, 26 January 2006 [en ligne] http://www.homepages.ucl.ac.uk/ tcrndfu/ Abot/Millet\%20Handout06.pdf.

Fuller D.Q., Boivin N., Hoogervorst T. \& Allaby R. 2011. Across the Indian Ocean: the prehistoric movement of plants and animals. Antiquity 85, p. 544-558.

Fuller D.Q. \& Korisettar R. 2004. Early plant domestications in southern India: some preliminary archaeobotanical results. Vegetation History and Archaeobotany 13 , p. 115-129.

Fuller D.Q., Qin L., Zheng Y., Zhao Z., Chen X., Hosoya L.A. \& Sun, G.-P. 2009. The domestication process and domestication rate in rice: spikelet bases from the Lower Yangtze. Science 323, p. 1607-1610.

Fung Ping Shan Museum 1985. Ceramics from Tang and Song Kilns in Guangdong. Hong Kong, University of Hong Kong.

Fung Ping Shan Museum 1992. Ceramics Finds from Jingdezhen. Hong Kong, University of Hong Kong.

Gallant T.W. 1985. The agronomy production and utilization of sesame and linseed in the Graeco-Roman world.
In J.N. Postgate \& M.A. Powell (éds), Bulletin on Sumerian Agriculture 2. Cambridge University Press, p. 153-158.

GARDIN J.-C. 1963. Lashkari Bazar. Une résidence royale ghaznévide. II Les trouvailles. Céramiques et Monnaies de Lashkari Bazar et de Bust. Mémoires de la Délégation Archéologique Française en Afghanistan 18. Paris, Librairie C. Klincksieck.

Ghazanfar S.A. 2003. Flora of Oman vol. 1. PiperaceaePrimulaceae. National Botanic Garden, Belgique, Scripta Botanica Belgica 25.

GILMORE M. 1985. A preliminary report on the first season of excavations at al-Mabiyat, an early Islamic site in the northern Hejaz. Atlal 9, p.109-125.

GoiteIN S.D. 1954. Two Eye-Witness Reports on the Expedition of the King of Kish (Qais) against Aden. Bulletin of the School of Oriental and African Studies 16, p. 247-257.

Goitein S.D. \& Friedman M.A. 2008. India Traders of the Middle Ages: Documents from the Cairo Geniza: India Book. Leyde, Boston, Brill.

GoldsteIn S.M. 2005. Glass from Sasanian antecedents to European imitations. The Nasser D. Khalili Collection of Islamic Art, vol. XV. Londres.

Golvin L. 1965. Recherches archéologiques à la qal'a des Banu Hammad. Paris.

Gorin-Rosen Y. 1997. Excavation of Courthouse Site at Akko: Medieval Glass Vessels (Area Ta). Atiqot 31, p. $75-85$.

Grenet F. \& Rapin C. 1998. De la Samarkand antique à la Samarkand islamique. In R. Gayraud (éd.), Archéologie islamique. Actes du colloque international du Caire 3-7 février 1993. Le Caire, IFAO, p. 387-402.

Grube E.J. 1995. Sgraffiato wares. In E.J. Grube (éd.), Cobalt and Lustre. The first centuries of Islamic pottery. The Nasser D. Khalili Collection of Islamic Art, vol IX. Londres, The Nour Foundation in association with Azimuth Editions and Oxford University Press, p. 115-116.

Guangdong sheng bowuguan 廣東省博物館1981. Chaozhou Bijiashan Songdai yaozhi fajue baogao 潮州筆 架山宋代窯址發掘報告 [Rapport des fouilles du site des fours de Bijiashan des Song à Chaozhou]. Pékin, Wenwu chubanshe.

Guangzhou shi wenwu guanli weiyuanhui 1958. Xicun yao yizhi 西村窯遺址 [Le site des fours de Xicun]. Pékin, Wenwu chubanshe.

Guangzhou shi wenwu guanli weiyuanhui 廣州市文物管 理委員會 \& Xianggang zhongwen daxue wenwuguan 香 港中文大學文物館1987. Guangzhou Xicun yao 廣州西 村窯 [Les fours de Xicun à Guangzhou]. Hong Kong, The Chinese University of Hong Kong.

Guillot C. (dir.) 2003. Histoire de Barus Sumatra. Le site de Lobu Tua, II, Etude archéologique et Documents. Cahier d'Archipel 30. Paris.

Guillot C. 2003. Le verre. In C. Guillot (dir.), Histoire de Barus Sumatra. Le site de Lobu Tua, II. Etude archéologique et documents. Paris, Cahier d'Archipel 30. p. 223-274. 
AL-HAMDĀNī 1884-1891. Sifat jazīrat al-'Arab. D. H. Müller (éd.). 2 vol. Nouvelle édition de M. al-Akwa', Șan'ā’, Markaz al-dirāsāt wa-l-buhūth al-yaman̄̄, 1983.

AL-Ḥ̄mid Ș. 1968. Ta'rīkh Haḍramawt. Șan‘ā', Maktabat

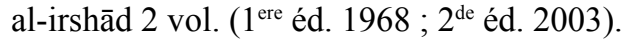

Hansman J. 1985. Julfar, an Arabian port. Its settlement and far-eastern ceramic trade from the 14th to the 18th centuries. Londres, the Royal Society of Great Britain and Ireland.

Harding G.L. 1964. Archaeology in the Aden protectorate. Londres, Her Majesty's Stationery Office.

Hardy-Guilbert C. 1984. Les niveaux islamiques du secteur Apadana-Ville Royale. Cahiers de la Dafi 14, p. 121-209.

Hardy-Guilbert C. 2001. Archaeolgical research at al-Shihr, the Islamic port of Hadramawt, Yemen (19961999), Seminar for Arabian studies, vol. 31, p. 69-79.

HaRdy-GuilBert C. 2005a. La "mustard ware” yéménite, un marqueur chronologique du XIV ${ }^{\mathrm{e}}$ siècle. Taoci 4 . Actes $\mathrm{du}$ colloque Chine-Méditerranée. Routes et échanges de la céramique avant le XVI siècle. Paris, Société Française d'Etude de la Céramique Orientale, Musée Cernuschi, p. $117-125$.

HARDY-Guilbert C. 2005b. The harbour of al-Shihr, Hadramawt, Yemen: sources and archaeological data on trade. Proceedings of the Seminar for Arabian Studies 35, p. 71-85.

Hardy-Guilbert C. \& Ducatez G. 2004. Al-Shihr, porte du Hadramawt sur l'océan Indien. Annales Islamologiques 38, p. 95-157.

Hardy-Guilbert C. \& Le Maguer S. 2010. Chihr de l'encens (Yémen). Arabian archaeology and epigraphy 21, p. 46-70.

Hardy-Guilbert C. \& Rougeulle A. 1995. Archaeological research on the Islamic period in Yemen: preliminary notes on the French expedition, 1993. Proceedings of the Seminar for Arabian Studies 25, p. 29-44.

Hardy-Guilbert C. \& Rougeulle A. 1997a. Ports islamiques du Yémen. Prospections archéologiques sur les côtes yéménites 1993-95. Archéologie Islamique 7, p. 147-196.

Hardy-Guilbert C. \& Rougeulle A. 1997b. Al-Shihr and the southern coast of Yemen: preliminary notes on the French archaeological expedition, 1995. Proceedings of the Seminar for Arabian Studies 27, p. 129-140.

Hardy-Guilbert C. \& Rougeulle A. 2003. La céramique des « Temples I et II ». La céramique et les verres du monastère. In M-J. Steve et al., L'île de Khârg. Une page de l'histoire du golfe Persique et du monachisme oriental. Civilisation du Proche-Orient, série I ; Archéologie et Environnement, vol. I. Neuchâtel-Paris, p. 24-40, 131-149.

Harlan J.R. 1995. The tropical African cereals. In T. Shaw, P. Sinclair, B. Andah \& A. Okpoko (éds), The Archaeology of Africa: Food, Metals and Towns. New York, World Archaeology, Routledge, p. 53-60.
HAsson R. 1979. Early Islamic Glass. Jérusalem.

Henein N.H. 1997. Poteries et potiers d'al-Qasr, oasis de Dakhla. Le Caire, IFAO, Bibliothèque d'Etude 116.

Hentschel F. 2009a. Gobular Jars. In Bass et al. 2009, chapitre 27 , p. 310-319.

Hentschel F. 2009b. Basket Bowls. In Bass et al. 2009, chapitre 11, p. 122-130.

Ho Ch. 1995. Turquoise jars and other West Asian ceramics in China. Bulletin of the Asia Institute N.S. 9, p. 19-31.

Ho Ch. 2001. The Ceramic Boom in Minnan during Song and Yuan Times. In A Schottenhammer (éd.), The Emporium of the World. Maritime Quanzhou, 1000-1400. Leiden, Brill; Boston, Köln, p. 237-282.

Hobson R.L. 1937. Pottery fragments from southern Persia and the northern Penjab. In A. Stein, Archaeological reconnaissance in north-western India and south-eastern Iran. Londres, p. 244-247.

Hoffman E.S. 1984. Botanical remains. In H.T. Wright, C. Sinopoli, L. Wojnaroski, E.S. Hoffman, S.L. Scott, R.W. Redding \& S.M. Goodman, Early seafarers of the Comoro Islands: The Dembeni phase of the 9th-10th centuries AD. Azania 19/1, p. 13-59.

Horton M. 1996. Shanga. The archaeology of a Muslim trading community on the coast of East Africa. Monograph series, Memoir 14. Londres, British Institute in Eastern Africa.

Horton M. 2005. Siraf and East Africa. In Proceedings of the International Congress of Siraf Port, 14-16 nov. 2005. Bushehr, Islamic Republic of Iran.

Horton M. à paraître. Zanzibar and Pemba. The Archaeology of an Indian Ocean Archipelago. Londres.

Horton M., Brown H.M. \& Oddy W.A. 1986. The Mtambwe Hoard. Azania 21, p. 115-123.

HUANG F., 黃富蓮 2005. [福州]: 福建美术出版社 [Fuzhou]: Fujian mei shu chu ban she.

Hugues-Stanton P. \& Kerr R. (éds) 1980. Kiln sites of ancient China. Recent finds of Pottery and Porcelain. Londres, the Oriental Ceramic Society.

Huizhou diqu wenhuaju 惠州地區文化局, Huizhou shi wenhuaju 惠州市文化局 \& Guangdong bowuguan 廣東 博物館 1977. Guangdong Huizhou Beisong yaozhi qingli jianbao 廣東惠州北宋窯址清理簡報 [Rapport preliminaire des fouilles du site des fours de Huizhou des Song du Nord au Guangdong]. Wenwu 1977/8, p. 46-58.

Idemitsu bijutsukan 1982, 1949-1981 kinnen hakken no yôshi shutsudo chûgoku tôji ten - haken no Chukogu tôji ten ? [Exposition sur les céramiques chinoises récemment découvertes sur les sites d'officines de potiers]. Tokyo, Idemitsu bijutsukan.

IBN BAṬṬṬA 1853-1859. Tuḥfat al-nuz̧āār fì Gharā'ib al-amșār wa-'ăgā'ib al-asfār. C. Defremery et B. R. Sanguinetti (éd. et trad.). Paris, 4 vol. 
IвN ḤĀTIm 1974. Kitāb al-Simt al-ghālì al-taman fì akhbār al-mulūk min al-Ghuzz bi-l-Yaman. G. R. Smith (éd.) sous le titre : The Ayyubids and Early Rasulids in the Yemen (567-694/1173-1295). Londres, E. J. W. Gibb Memorial, 2 vol.

IBN HaWQAL 1964. Kitāb șūrat al-arḍ. J. H. Kramers (éd.). Leyde, Brill, $2^{\mathrm{e}}$ éd. (1ere éd. 1938); G. Wiet (trad. fr.), La configuration de la Terre. Paris-Beyrouth, 1964.

IBN KHURRADĀDHBIH 1889. Kitāb al-masālik wa-l-mamālik. M. J. G. De Goeje (éd.). Leyde, Brill.

IBN AL-MUJĀWIR 1951. Silfat bilād al-Yaman wa-Makka wa-ba'd al-Hijāz al-musammā Ta'rīkh al-mustabșir, éd. O. Löfgren. Leyde, Brill.

AL-IDRīsī 1971. Kitāb Nuzhat al-mushtāq fì 'khtirāq al-āfāq. A. Bombaci, U. Rizzitano, R. Rubinacci \& L.V. Vabliere (éds), Opus Geographicum 1, 52 fasc. 1. Leyde (trad. Guy Ducatez).

Insoll T. 2001. Dahlak Kebir, Eritrea: from Aksumite to Ottoman. Adumatu 3, p. 39-50.

L'Islam dans les collections nationales 1977. Paris, RMN, catalogue d'exposition.

JACKSON-TAL R.E. 2007. Glass Vessels from En-Gedi. In Y. Hirschfeld (éd.), En-Gedi Excavations II, Final Report (1996-2002). Jerusalem, chapitre 8, p. 474-506.

JANPOLADIAN H.M. 1974. The Medieval Glassware of Dvin. Yerevan, Archaeological Monuments and Specimens of Armenia 7.

JĀZIM M. 'A. (éd.) 2008. Irtifā' al-dawla al-mu'ayyadiyya/Livre des revenus du sultan rassoulide al-Mu'ayyad Dāwūd. Șan'ā', CEFAS-DAI.

JENNINGS S. 2004-2005. Vessel Glass from Beirut, BEY 006, 007 and 045. Berytus 48-49.

Jiangxi sheng wenwu gongzuodui \& Nanfeng xian wenhuaguan 南豐縣文化館 1985. Jiangxi Nanfeng Baishe yao diaocha jishi 江西南豐白舍窯調查紀實 [Les prospections du site de fours de Baishe à Nanfeng au Jiangxi]. Kaogu 1985/3, p. 222-233.

Jiangxi sheng wenwu gongzuodui 1985. Jiangxi Jingdezhen Liujiawan guci yaozhi diaocha 江西景德鎮 劉家灣古瓷窯址調查 [Les prospections du site de fours de Liujiawan à Jingdezhen au Jiangxi]. Kaogu 1985/4, p. $365-370$ et 359 .

Jiangxi sheng wenwu kaogu yanjiusuo et al. 1999. Fengcheng guibao-Jiangxi peihe jijian chutu wenwu jingping 封塺瑰寶 江西配合基本建設出土文物精 品 [Les trésors enfouis - les plus beaux objets exhumés des fouilles de sauvetage au Jiangxi]. Nanchang, Jiangxi meishu chubanshe.

Jiangxi sheng wenwu kaogu yanjiusuo 江西省文物考 古研究所 \& Jingdezhen taoci lishi bowuguan 景德鎮陶 瓷歷史博物館 2001. Jingdezhen Hutian yao H qu fushu zhugandao fajue jianbao” 景德鎮湖田窯 H 區附屬主幹 道發掘簡報 [Le rapport préliminaire de la zone des axes principaux du quartier $\mathrm{H}$ du site des fours de Hutian à Jingdezhen]. Wenwu 2001/2, p. 42-62.
Jiangxi sheng wenwu kaogusuo \& Jingdezhen minyao bowuguan 景德鎮民窯博物館 2007. Hutian yao 湖田窯 [Les fours de Hutian]. Pékin, Wenwu chubanshe.

Jiangxi sheng wenwu kaogusuo, Ganzhou diqu bowuguan 贑州地區博物館 \& Ganzhou shi bowuguan 贑州市博物 館 1990. Jiangxi Ganzhou Qilizhen yaozhi fajue jianbao 江西贑州七裡鎮窯址發掘簡報 [Rapport préliminaire des fouilles du site de fours de Qilizhen à Ganzhou au Jiangxi]. Jiangxi wenwu 江西文物 1990/4, p. 3-23.

Jiujiang shi wenwu baohu guanlisuo 九江市文物保護管 理所 1990. Jiangxi Jiujiang Beisong mu 江西九江北宋 墓 [Une tombe des Song du Nord à Jiujiang au Jiangxi]. Wenwu 1990/9, p. 19-21.

JoHnSON L.W. 1992. The plant remains. In H.T. Wright, Early Islam, Oceanic Trade and Town Development on Nzwani: The Comorian Archipelago in the XIth-XVth Centuries AD. Azania 27/1, p. 81-128.

Jörg Ch.A. 2007. The Ca Mau Porcelain Cargo. In Made in Imperial China. 76,000 Pieces of Chinese Export Porcelain from the Ca Mau Shipwreck, circa 1725, Sotheby's, auction 29, 30 \& 31 January 2007. Amsterdam, p. 16-19.

JumA M.A. 2004. Unguja Ukuu on Zanzibar: an archaeological study of early urbanism. Studies in Global Archaeology 3. Uppsala, Uppsala University.

Kawatoko M. 1993. Preliminary Survey of 'Aydhâb and Badi‘ Sites. Kush 16, p. 186-225.

Kawatoko M. 1996. A Port City Site on the Sinai Peninsula Al-Tür. The 12th expedition in 1995 (A summary report). Tokyo, Middle Eastern Culture Center in Japan, Committee for Egyptian Islamic Aechaeology.

Kawatoko M. \& Shindo Y. 2009. Artifacts of the Islamic Period Excavation in the Rayal al-Tur, South Sinai, Egypt, Ceramics/glass/Painted Plaster, Research Centre for Islamic Area Studies/Organization for Islamic Area Studies, Waseda, University, Tokyo.

Keall E. 1983. The dynamics of Zabid and its hinterland: the survey of a town on the Tihama plain of North Yemen. World Archaeology 14/3, p. 378-392.

Keall E. 1992. Smokers' pipes and the fine pottery tradition of Hays. Proceedings of the Seminar for Arabian Studies 22, p. 29-46.

KeAll E. 2001. The evolution of the first coffee cups in Yemen. In M. Tuchscherer (éd.), Le commerce $d u$ café avant l'ère des plantations coloniales : espaces, réseaux, sociétés $\left(x v^{e}-X I X^{e}\right.$ siècle). Cahier des Annales Islamologiques 20, p. 35-50.

Keall E. 2008. The changing positions of Zabîd's Red Sea port sites. Chroniques yéménites 15, p. 111-125.

KENNET D. 2004. Sasanian and Islamic Pottery from Ras al-Khaimah, Classification, chronology and analysis of trade in the Western Indian Ocean. BAR International Series 1248. Oxford, Archaeopress.

Kervran M. 1977. Les niveaux islamiques du secteur oriental du tépé de l'Apadana, II le matériel céramique. Cahiers de la Dafi 7, p. 75-161. 
Kervran M. 1983. Deux forteresses islamiques de la côte orientale de 1'Arabie. Proceedings of the Seminar for Arabian Studies 13, p. 71-77.

Kervran M. 1996. Indian ceramics in southern Iran and eastern Arabia, Repertory, classification and chronology. In H.P.Ray \& J.-F. Salles (éds), Tradition and Archaeology, Early Maritime Contacts in the Indian Ocean. Proceedings of the International Seminar Techno-Archaeological Perspectives of Seafaring in the Indian Ocean, 4th cent. B.C.-15th cent. A.D., New-Delhi, February 28-March 4, 1994. Delhi, Manohar, p. 37-58.

Kervran M. 2004. Archaeological research at Suhar 1980-1986. Journal of Oman Studies 13, p. 263-381.

Kervran M., Hiebert F. \& Rougeulle A. 2005. Qal'at al-Bahrain. A trading and military outpost. Indicopleustoi, Archaeologies of the Indian Ocean 4. Turnhout, Brepols.

KHAN F.A. 1976. A preliminary report on the recent archaeological excavations at Banbhore. Karachi, Department of Archaeology and Museums, Anjuman Press.

Kirkman J. 1967. Fort Jesus. Mombasa, Nairobi, Museum Trustees of Kenya.

Kirkman J. 1974. Fort Jesus, A Portuguese fortress on the East Arican Coast, Oxford, The Clarendon Press.

Kitâb 'ajâ'îb al-Hind, Livre des merveilles de l'Inde par le capitaine Bozorg fils de Chahriyâr de Râmhormoz, texte arabe publié d'après le manuscrit de $\mathrm{M}$. Schefer, collationné sur le manuscrit de Constantinople par P.A. Van Der Lith, traduction française par L. M. Devic, E.J. Brill, Leyde, 1883-1886, réimp. 1993, Publications of the Institute for the History of Arabic-Islamic Science, F. Sezgin éd. J.W. Goethe University, Francfort, Islamic Geography.

Klose J. 1994. Excavated Oriental Ceramics from the Cape of Good Hope : 1630-1830, Transactions of Oriental Ceramic Society, vol. 57, p. 69-95.

Krahl R., GuY J., Raby J. \& Wilson K. 2010. Shipwrecked: Tang treasures and monsoon winds. Washington D.C., Arthur M. Sackler Gallery, Smithsonian Institution.

KRÖGER J. 1995. Nishapur. Glass of the Early Islamic Period. New York, the Metropolitan Museum of Art.

Kunn D. 1994. Burial in Song China. Heidelberg, Edition Forum.

Kunn D. 1996. A Place for the Dead. An Archaeological Documentary on Graves and Tombs of the Song Dynasty (960-1279). Heidelberg, Edition Forum.

KÜRSCHNER H. 1998. Chapter 4. Biogeography and introduction to végétation. In S.A. Ghazanfar \& M. Fisher (éds), Vegetation of the Arabian Peninsula. Dordrecht/ Boston/London, Kluwer Academic Publishers, Geobotany Series 25, p. 63-98.

Lane A. \& SerJeant R.B. 1948. Pottery and glass fragments from the Aden littoral, with historical notes. Journal of the Royal Asiatic Society, octobre 1948, p. 108-133.

Langenheim J.H. 2003. Plant Resins: Chemistry, Evolution, Ecology, and Ethnobotany. Cambridge, Timber Press.
Lester A. 2003. Glass Bottles and Vials from Tiberias. In Annales du $15^{e}$ Congrès de L'Association Internationale pour l'Histoire du Verre (New York, Corning 2001). Nottingham, p. 158-164.

Lester A., Arnon Y.D. \& Pollak R. 1999. The Fatimide Hoard from Caesarea: a preliminary Report. In M. Barrucand (dir.), L'Egypte fatimide, son art, son histoire, actes du colloque de Paris, mai 1998. Paris, p. 233-246.

Li B. 李炳炎 2004. Chaozhou yao 潮州窯 [Les fours de Chaozhou]. Shantou, Shantou daxue chubanshe.

Li D. 李德金 1990. Fujian Jianyang xian Shuiji Beisong Jian yao yizhi fajue jianbao 福建建陽縣水吉北宋建窯 遺址發掘簡報 [Rapport préliminaire des fouilles du site des fours de Jian à Shuiji dans le district de Jianyang au Fujian]. Kaogu 1990/12, p. 1095-1099 et 1089.

Li D. 李德金 et al. 2003. Zhonghua qinghua ci 中華青花 [Les porcelaines bleu et blanc chinoises], Pékin, Renmin chubanshe.

Li H. 李海根 1990. Ganzhou Qilizhen yao Wutoutang chutu ciqi 贑州七裡窯烏頭塘出土瓷器 [La céramique trouvée sur le site de Wutoutang à Qilizhen à Ganzhou] Jiangxi wenwu 1990/4, p. 24-30.

LI J. 栗建安 1994. 福建的建窯係黑婇茶碗 [Les bols à thé du groupe des fours de Jian au Fujian], Chadô shiryôkan, Fukken shô hakubutsukan, Karamono temmoku - Fukken shô kenyô shutsudo temmoku to Nihon no densei temmoku, [Les bols à thé en gris à couverte brun-noir chinois objets provenant des fouilles des fours de Jian au Fujian et pièces de collection au Japon]. Kyoto, Chadô shiryôkan, p. 270-279.

Li J. 栗建安 2012. Dongjian xishu-Chaozhou yao yu zhoubian yaociye de guanxi jiqi chanping waixiao de ruogan wenti 東漸西輸一潮州窯與週邊瓷窯業的 關係及其產品外銷的若干問題 [L'introduction des techniques par l'Est et l'exportation des produits vers l'Ouest- Questions relatives aux rapports entre les fours de Chaozhou et les fours des environs, ainsi qu'à la commercialisation de leurs productions ]. In Huang Ting \& Li Bingyan (éds), Nanguo cizhen-Chaozhou yao xueshu yanjiu taolunhui lunwenji 南國瓷珍一潮州窯學術研究 討論會論文集 [Les trésors de la céramique du Sud-Actes du colloque sur les fours de Chaozhou]. Hong Kong, The Art Museum of the Chinese University of Hong Kong, p. $95-110$.

Li Zh. 李仲謀 1998. Qingbai ci 青白瓷 [Les qingbai]. Shanghai, Shanghai renmin meishu chubanshe.

Liebner H. 2014. The Siren of Cirebon. A Tenth-Century Trading Vessel Lost in the Java Sea. PhD Dissertation, The University of Leeds School of Modern Languages and Cultures East Asian Studies.

Lin Sh. 林士民 1999. Qingci yu Yue yao 青瓷與越窯 [Les grès à couverte verte et les fours de Yue]. Shanghai, Shanghai guji chubanshe

LiU T. 劉濤 2004. Song Liao Jin jinian ciqi 宋遼金紀年墓 [Les tombes datées des Song et des Liao]. Pékin, Wenwu chubanshe. 
LIU X. 劉新圓 \& BAI K. 白琨 1980. Jingdezhen Hutian yao geqi dianxing wanlei de zaoxing tezheng jiqi chengyin kao 景德鎮湖田各期典型碗類的造型特徵及其成因考 [Recherches sur les origines techniques des caractéristiques morphologiques des bols représentatifs des différentes phases de la production de Hutian du groupe des fours de Jingdezhen]. Wenwu 1980/5, p. 85-92.

LiU Y. 劉岩, QIN D. 秦大樹 \& KIRIAMA H. 齐里亚马·赫曼 2012. Kengniya binghaisheng Gedi gucheng yizhi chutu Zhongguo ciqi 肯尼亞濱海省格迪古城遺址出土中國瓷 器 [La céramique chinoise trouvée sur le site de l'ancienne cité de Gedi dans la province côtière du Kenya]. Wenwu 2012/11, p. 37-60.

Lledó B. 2009a. Handled Jars with threaded Rims. In Bass et al. 2009, chapitre 31, p. 353-354.

Lledó B. 2009b. Ellipsoids Bowls. In Bass et al. 2009, chapitre 14, p. 177-181.

Lledó B. 2009c. Flared Bowls. In Bass et al. 2009, chapitre 12, p. 131-160.

LLEDó B. 2009d. Hemispherical bowls. In Bass et al. 2009, chapitre 13, p. 161-175.

Lledó B. 2009e. Demijohns and other large globular Bottles. In Bass et al. 2009, chapitre 29, p. 335-352.

Luo Y. 羅宜生 2005. Zhangping yao 漳平窯 [Les fours de Zhangping]. Fuzhou, Fujian meishu chubanshe.

AL-MALĀḤ̄ 'A. H. 1989. Ta'rīkh al-șirā' al-ḥumūmī al-qu'ayțī wa-dawāfi'ihi (1867-1967). Al-Mukalla, Université d'Aden, Faculté d'éducation d'al-Mukalla.

Marçais G. \& Poinssot L. 1952. Objets Kairouanais $I X^{e}$ au XII siècle. Reliures, verreries, cuivres et Bronzes, Bijoux, Notes et Documents XI-fasc.2. Tunis.

Margariti R.E. 2007. Aden and the Indian Ocean Trade: 150 Years in the Life of a Medieval Arabian port. Chapel Hill, the University of North Carolina Press.

Al-Mas'ūdī 1962. Les prairies d'or. Ch. Barbier de Meynard et A. Pavet de Courteille (trad.), revue par Ch. Pellat. Paris, Société Asiatique, volume 1.

Al-Muqaddasī 1906. Aḥsan al-taqāsìm fì ma'rifat al-aqālìm. M. J. de Goeje (éd.). Leyde, Brill.

MARTIN N. 2010. Les productions céramiques de l'océan Indien occidental : implications culturelles au carrefour d'influences. Thèse de doctorat sous la direction de C. Allibert, INALCO, Paris, n.p.

Mason R.B., Hallett J.R. \& Keall E.J. 1989. Provenance of Islamic pottery from Yemen: INAA and petrographic analysis. 25th International Archaeometry Symposium Proceedings. Athens, p. 543-555.

Mason R.B. \& Keall E. 1988. Provenance of local ceramic industry and the characterization of imports: petrography of pottery from medieval Yemen. Antiquity 62, p. 452-463.

Mason R.B. \& Keall E. 1991. The 'Abbasid glazed wares of Siraf and the Basra connection: petrographic analysis. Iran 29, p. 51-66.
Mathe C., Archier P., Nehme L. \& Vieillescazes C. 2009. The study of Nabataean organic residues from Madâ'in Sâlih, ancient Hegra, by gas chromatography-mass spectrometry. Archaeometry 51(4), p. 626-636.

Mathe C., Connan J., Archier P., Mouton M. \& Viellescazes C. 2007. Analysis of frankincense in archaeological samples by gas chromatography-mass spectrometry. Annali di Chimica 97, p. 433-445.

Mathe C., Culioli G., Archier P. \& Vieillescazes C. 2004. Characterization of archaeological frankincense by gas chromatography-mass spectrometry. Journal of Chromatography A 1023, p. 277-285.

Mathew G. 1956. Chinese Porcelain in East Africa and on the Coast of South Arabia, Oriental Art, vol. 2, p. 50-55.

Matthews S.D. 2009. Serving Dishes. In Bass et al. 2009, chapitre 7, p. 93-102.

McCorriston J. \& Johnson Z. 1998. Agriculture and animal husbandry at Ziadid Zabid, Yemen. Proceedings of Seminar for Arabian Studies 28, p. 175-188.

McNicoll A. 1974. Archaeological investigations in Bahrain 1973-4. Bahrain, Directorate of Tourism and Archaeology, rapport non publié.

La Médecine au temps des Califes 1996. Paris, RMN, catalogue d'exposition.

Meyer C. 1992. Glass from Quseir Al-Qadim and the Indian Ocean Trade. Chicago, Studies in Ancient Oriental Civilization 53.

Meyer C., Todd J.M. \& Beck C.W. 1991. From Zanzibar to Zagros: a copal pendant from Eshnunna. Journal of Near Eastern Studies 50, p. 289-298.

Miller N. 1981. Plant remains from Ville Royale II, Susa. Cahier de la Délégation Archéologique Française en Iran 12, p. 137-142.

Mills J.S. \& White R. 1994. The organic chemistry of museum objects. Oxford, Butterworth-Heinemann.

Monod T. 1978. Sur un site à bracelets de verre des environs d'Aden. Raydân 1, p.111-124.

Morgan P. 1991. New Thoughts on Old Hormuz: Chinese Ceramics in the Hormuz Region in the Thirteenth and Fourteenth Centuries. Iran 29, p. 67-83.

Morgan P. 1995. Sgraffiatos. Types and distribution. In E.J. Grube (éd.), Cobalt and Lustre. The first centuries of Islamic pottery. The Nasser D. Khalili Collection of Islamic Art, vol IX. Londres, The Nour Foundation in association with Azimuth Editions and Oxford University Press, p. 119-123.

Morrison H. 1984. The Glass. In N. Chittick, Manda: Excavations at an Island Port on the Kenya Coast. Nairobi, British Institute in Eastern Africa, memoire 9, p. 159-179.

Morrison H. 1987. Unpublished Medieval Glass from the Island of Mafia in East Africa. Annales du $10^{e}$ Congrès de L'Association Internationale pour l'Histoire du Verre (Madrid-Ségovie 1985). Amsterdam, p. 299-304. 
Moulins de D., Phillips C. \& Durrani N. 2003. The archaeobotanical record of Yemen and the question of Afro-Asian contacts. In K. Neumann, A. Butler \& S. Kahlheber (éds), Food, Fuel and Fields. Progress in African Archaeobotany. Köln, 15 Africa Praehistorica. Monographien zur Archäologie und Umwelt Afrikas. Heinrich-Barth-Institut, p. 213-227.

Mouton M., SAnlaville P. \& Suire J. 2006. Le port sudarabique de Qāni' : paléographie et organisation urbaine. Comptes Rendus de l'Académie des Inscriptions \& Belles Lettres avril-juin 2006, p. 777-808.

Mukherjee A.J., Rossberger E., James M.A., Pfälzner P., Higgitt C.L., White R., Peggie D.A., Azar D. \& Evershed R.P. 2008. The Qatna lion: scientific confirmation of Baltic amber in late Bronze Age Syria. Antiquity 82(315), p. 49-59.

AL-MuQAdDAsī 1897. Ahsan al-taqāsīm fì ma'rufati-l-aqālìm. G.S.A. Ranking \& R.F. Azoo (éds et trad.), Ahsan al-Taqâsîm fî ma'rufati-l-aqâlîm, al-Muqaddasî. Calcutta, Bibliotheca Indica, Asiatic Society of Bengal.

Nanjing shi bowuguan 南京市博物館 1987. Jiangsu Lianyungang shi Songdai muzang de qingli 江蘇連雲港 市宋代墓葬的清理 [Le dégagement de la tombe des Song à Lianyungang au Jiangsu]. Kaogu 1987/3, p. 232-237.

Neimenggu zizhiqu wenwu kaogu yanjiusuo 內蒙古自 治區文物考古研究所 \& Zhelimumeng bowuguan 哲裏 木盟博物館 1993. Liaoguo Chen gongzhu mu 遼國陳公 主墓 [La tombe de la princesse Chen des Liao]. Pékin, Wenwu chubanshe.

Nesbitt M., Simpson S. \& Svanberg I. 2010. History of rice in Western and Central Asia. In S.D. Sharma (éd.), Rice: origin, antiquity and history. Enfield, Science Publishers, p. 312-344.

Newton L. 2007. Al Qisha: archaeological investigations at an Islamic period Yemeni village. Proceedings of the Seminar for Arabian Studies 37, p. 171-186.

Newton L.S. 2009. A landscape of pilgrimage and trade in Wadi Masila, Yemen. Al-Qisha and Qabr Hud in the Islamic period. BAR International Series 1899. Oxford, Archaeopress.

Orton N.P. 1991. Red Polished Ware in Gujarat: A Catalogue of Twelve Sites. In V. Begley \& R.D. De Puma (éds), Rome and India. The Ancient Sea Trade. Oxford, Oxford University Press, p. 46-81.

OUYANG X. 歐陽希君 2005. Fuqing yao 福清窯 [Les fours de Fuqing]. Fuzhou, Fujian meishu chubanshe.

Palavestra A. \& Krstic V. 2006. The magic of amber. Belgrade, Archaeological monographies National Museum 18.

PENG Sh. 彭善國 2013. Liao Jin Yuan taoci kaogu yanjiu 遼金元陶瓷考古研究 [Recherches archéologiques sur la céramique des Liao, des Jin et des Yuan]. Pékin, Kexue chubanshe.

PENG Sh. 彭善國 2002. Liaodai qingbai ciqi chutan 遼代 青白瓷器初探 [Recherches sur les qingbai trouvés dans des tombes des Liao]. Kaogu 2002/12, p. 64-74.
PENG Sh. 彭適凡 \& FAN F. 范鳳妹 (éds) 1998. Dated qingbai Wares of the Song and Yuan Dynasties. Hong Kong, Ching Leng Foundation.

Perret D. \& Riyanto S.1998. Les poteries proche-orientales engobées à décor incise et jaspé de Lobu Tua. In C. Guillot (dir.), Histoire de Barus, Le site de Lobu Tua, II, Etude archéologique et Documents. Cahier d'Archipel 30. Paris, p. 169-188.

Phillipson D.W. 1979. Some Iron Age sites in the lower Tana Valley. Azania 14, p. 155-160.

Pirazzoli-t'Serstevens M. 1988. La céramique chinoise de Qal 'at al-Suhâr. Arts asiatiques 43, p. 87-105.

Piacentini V.F. 1999. Merchant Families in the Gulf. A mercantile and cosmopolitan dimension: the written evidence $\left(11^{\text {th }}-13^{\text {th }}\right.$ centuries AD). Proceedings of the ARAM 11th International Conference. Cultural Interchange in the East of the Arabian Peninsula. Oxford, Oxford University Press 11/1, p. 143-157.

Piacentini V.F. 2004. The mercantile empire of the Tî̄bīs: economic predominence, political power, military subordination. Proceedings of the Seminar for Arabian Studies 34, p. 251-260.

Piacentini V.F. 2005. Sohar and the Daylamī Interlude (356-443/967-1051). Proceedings of the Seminar for Arabian Studies 38, p. 195-206.

Pirazzoli-t'Serstevens M. 1985. Chinese Ceramics Excavated in Bahraîn and Oman, In Mikami Tsugio hakushi kiju kinen ronbun shû [Le livre en hommage au 70 anniversaire de Mikami Tsugio], Kôkogaku hen [Volume en archéologie], Tôkyô, Heibonsha, p. 315-335.

Pirazzoli T'Serstevens M. 1988. La céramique chinoise de Qal' at al-Suhâr, Arts asiatiques, vol. 43, p. 87-105.

Ploug G., Oldenburg E., Hammershaimb E. \& Thomsen R. 1969. Hama. Fouilles et Recherches de la Fondation Carlsberg 1931-1938. Les petits objets médiévaux saufles verreries et poteries. Copenhague, Nationalmuseet.

Pollak R. 2000. Glass Vessels of a Fatimid Hoard from Caesarea Maritima. Annales du $14^{e}$ Congrès de L'Association Internationale pour l'Histoire du Verre (Venise-Milan 1998). Lochem, p. 238-242.

Pollak R. 2003. Early Islamic Glass from Caesarea: a Chronological and Typological Study. Annales $d u 15^{e}$ congrès de l'Association Internationale pour l'Histoire du Verre (New York-Corning 2001). Amsterdam, p. 165-170.

PotTs D.T. 2001. Ostrich distribution and exploitation in the Arabian Peninsula. Antiquity 75, p. 182-190.

Potts D. \& Mughannam A.S. 1978. Comprehensive Archaeological Survey Program. Preliminary report on the second phase of the eastern province survey, 1397/1977. Atlal 2, p. 7-27.

Pradines S. 2004. Fortifications et urbanisation en Afrique orientale. Cambridge Monographs in African Archaeology 58, BAR International Series 1216, Oxford, Archaeopress. 
Pradines S. 2009. L'île de Sanjé ya Kati (Kilwa, Tanzanie). Un mythe Shirâzi bien reel. Azania 44/1, p. 49-73.

Pradines S. 2010. Gedi, une cité portuaire swahilie. Islam médiéval en Afrique orientale. Le Caire, Institut Français d'Archéologie Orientale.

Price J. \& Worrell S. 2003. Roman, Sasanian and Islamic Glass from Kush, Ras al-Khaimah, United Arab Emirates: a Preliminary Survey. Annales du 15 e congrès de l'Association Internationale pour l'Histoire du Verre (New York- Corning 2001). Nottingham, p. 153-157.

PriestMan S. 2005. Settlement and ceramics in southern Iran: an analysis of the Sasanian and Islamic periods in the Williamson collection. Mémoire de Master, Departement d'Archéologie, Université de Durham, n.p.

PriestMan S. 2011. Opaque glazed wares: a review of the definition, dating and distribution of a key Iraqi ceramic export in the Abbasid period. Iran 49, p. 89-114.

Puche AciÉn C. 1993. El vidrio de época Almohade en Al-Andalus: primera aproximación formal. IVe Congreso de Arqueología Medieval Española, Sociedades en Transicion, Actes III. Alicante, p. 927-934.

Puche Acién C. 2003. Bubble-Rim Bottles. In Bass et al. 2009, chapitre 17, p. 214-222.

QIN D. 秦大樹 1991. Aiji Fusita yizhi zhong faxian de Zhongguo taoci 埃及福斯塔特遺址中發現的中國陶瓷 [La céramique chinoise exhumée sur le site de Fostât en Egypte]. Haijiaoshi yanjiu 海交史研究 1995/1, p. 79-90.

QIN D. 2000. Cizhouyao yaolu yanjiu ji beifang diqu ciyao fazhan de xiangguan wenti 磁州窯窯爐研究及北 方地區瓷窯發展的相關問題 [Recherches sur les fours à céramique des officines de potiers de Cizhou et sur l'évolution des techniques de fours dans le Nord]. Kaogu xue yanjiu 考古學研究 vol. 4, p. 266-303.

QIU L. 邱立誠 2008. Guangdong Song Yuan shiqi ciye de fazhan yu Leizhou yao de guanxi 廣東宋元時期瓷 業的發展與雷州窯的關係 [L'artisanat de la céramique au Guangdong sous les Tang et les Song et les rapports avec les fours de Leizhou]. In Yuedi kaogu qiusuo-Qiu Licheng lunwen xuan 粵地考古求索一邱立誠論文選 [Recherches archéologiques du pays de Yue-Recueil d'articles de Qiu Licheng]. Pékin, Kexue chubanshe, p. 464-480.

Radimilahy Ch. 1998. Mahilaka, An archaeological investigation of an early town in nortwestern Madagascar, Studies in African Arcaheology 15, Uppsala.

Rawson J. 1996. Changes in the Representation of Life and the Afterlife as Illustrated by the Contents of Tombs of the T'ang and Sung Periods. In M.K. Hearn \& J.G. Smith (éds), Arts of the Sung and Yüan. New York, The Metropolitan Museum of Art, p. 23-44.

REGERT M. 2004. Investigating the history of prehistoric glues by gas chromatography-mass spectrometry. Journal of separation science 27, p. 244-254.

REgerT M. 2009. Direct Mass Spectrometry to characterise lipid materials. In M.-P. Colombini \& F. Modugno (dir.),
Organic Mass Spectrometry in Art and Archaeology. Wiley, p. 97-129.

REgERT M. 2011. Analytical strategies for discriminating archaeological fatty substances from animal origin. Mass Spectrometry Reviews 30/2, p. 177-220.

Regert M., Devièse T., Le Hô A.-S. \& Rougeulle A. 2008. Reconstructing ancient Yemen commercial routes during the Middle-Ages using structural characterisation of terpenoid resins. Archaeometry 50/4, p. 668-695.

Regert M. \& Rolando C. 2002. Identification of Archaeological Adhesives Using Direct Inlet Electron Ionization Mass Spectrometry. Analytical Chemistry 74, p. 965-975.

Regert M., Langlois J., Laval E., Le Hô A.-S. \& PAgÈs-CAmagna S. 2006. Elucidation of molecular and elementary composition of organic and inorganic substances involved in 19th century wax sculptures using an integrated analytical approach. Analytica Chimica Acta 577, p. 140-152.

Regert M., Vacher S., Moulherat C. \& Decavallas O. 2003. Adhesive production and pottery function during the Iron Age at the site of Grand Aunay (Sarthe, France). Archaeometry 45/1, p. 101-120.

Reiche A. 1996. Early Islamic Glass from Bijan Island (Iraq). In K. Bartl \& S.R. Hauser (éds), Continuity and Change in Northern Mesopotamia from the Hellenistic to the Early Islamic Period (Proceedings of a Colloquium held at the Seminar für Vorderasiatische Altertumskunde, Frei Universität Berlin, 6th-9th April 1994). Berlin, p. 195-217.

Ridho A. \& McKinnon E.E. 1998. The Pulau Buaya Wreck, Finds from the Song Period. Jakarta, Himpunan Keramik Indonesia.

RIIS P.J. 1957. Les verreries. In P.J. Riis \& V. Poulsen, Hama : fouilles et recherches de la fondation Carlsberg, 1931-1938. Vol. $4 n^{\circ}$ 2. Les verreries et poteries médiévales. Copenhague.

Robert J.-N. 1997. De Rome à la Chine. Sur les routes de la soie au temps des Césars. Paris, Les Belles Lettres, $2^{\mathrm{e}}$ éd.

Robertshaw P., Wood M., Melchiorre E., Popelka-Filcoff R.S., GLASCOCK M.D. 2010. Southern African glass beads: chemistry, glass sources and patterns of trade. Journal of Archaeological Science 30, p. 1898-1912.

Ronquillo W.P. \& Tan R.C. 1994. Yue, Yue-type wares and other archaeological finds in Butuan, Philippines. In Ch. Ho (éd.), New Light on Chinese Yue and Longquan Wares, Hong Kong, p. 251-264.

Rougeulle A. 1991. Les importations extrêmes-orientales trouvées sur les sites de la période abbaside : contribution à l'étude du commerce moyen-oriental au Moyen-Âge. Thèse de doctorat sous la direction de J. Sourdel, Université de Paris IV-Sorbonne, Paris, n. p.

Rougeulle A. 1996. Medieval trade networks in the Western Indian Ocean (7-14 ${ }^{\text {th }}$ centuries). Some reflections 
from the distribution pattern of Chinese imports in the Islamic world. In H.P. Ray \& J.-F. Salles (éds), Tradition and Archaeology. Early Maritime Contacts in the Indian Ocean. Proceedings of the International Seminar TechnoArchaeological Perspectives of Seafaring in the Indian Ocean, 4th cent. B.C.-15th cent. A.D., New-Delhi, February 28-March 4, 1994. Delhi, Manohar, p. 159-180.

Rougeulle A. 1999. Coastal settlements in southern Yemen: the 1996-1997 survey expeditions on the Hadramawt and Mahra coasts. Proceedings of the Seminar for Arabian Studies 29, p. 123-136.

Rougeulle A. 2001. Notes on pre- and early Islamic harbours of Hadramawt (Yemen). Proceedings of the Seminar for Arabian Studies 31, p. 203-214.

Rougeulle A. 2003. Excavations at Sharma, Hadramawt, the 2001 and 2002 seasons. Proceedings of the Seminar for Arabian Studies 33, p. 287-307.

Rougeulle A. 2004. Le Yémen entre Orient et Afrique. Sharma, un entrepôt du commerce maritime médiéval sur la côte sud de l'Arabie. Annales Islamologiques 38, p. 201-253.

Rougeulle A. 2005a. The Sharma horizon. Sgraffiato wares and other glazed ceramics of the Indian Ocean trade (ca AD 980-1140). Proceedings of the Seminar for Arabian Studies 35, p. 223-246.

Rougeulle A. 2005b. Golfe Persique et mer Rouge : les routes de la céramique aux $\mathrm{X}^{\mathrm{e}}-\mathrm{XII}^{\mathrm{e}}$ siècles. Taoci 4 . Actes du colloque Chine-Méditerranée. Routes et échanges de la céramique avant le XVI siècle. Paris, Société Française d'Etude de la Céramique Orientale, Musée Cernuschi, p. 41-51.

Rougeulle A. 2007a. Ceramic production in mediaeval Yemen: the Yadhghat kiln site. Proceedings of the Seminar for Arabian Studies 37, p. 239-252.

Rougeulle A. 2007b. A medieval trade entrepôt at Khor Rori? The study of the Islamic ceramics from al-Hamr al-Sharqiya. In A. Avanzini (éd.), Khor Rori Report 2. Rome, «L'Erma » di Bretschneider, p. 645-667.

Rougeulle A. 2008. Hayrīğ, Šarwayn, Halfat, les ports anciens du Mahra (Yémen, c. IX ${ }^{\mathrm{e}}-\mathrm{XII}^{\mathrm{e}}$ siècles). Annales Islamologiques 42, p. 377-408.

Rougeulle A. 2010. The Qalhât project: new research at the medieval harbour site of Qalhât, Oman (2008). Proceedings of the Seminar for Arabian Studies 40, p. 303-319.

Rougeulle A. 2012. Syagros et autres établissements côtiers du Hadramawt préislamique. Note archéologique. In M.-F. Boussac, J.-F. Salles \& J.-B. Yon (éds), Autour du Périple de la Mer Erythrée. Topoi Supplément 11, p. 275-291.

Rougeulle A. à paraître. Islamic sites in Bahrain. Notes on the Bahrain Archaeological Map project. In P. Lombard (éd.), Proceedings of the International Conference 20 Years of Bahrain Archaeology, 1986-2006 (Manama, Bahrain National Museum, 9-12 December 2007). Bahrain.
Rougeulle A. \& Marchand S. 2011. Des siga sur la côte du Hadramawt (Yémen), témoins d'une attaque navale ? Les Cahiers de la Céramique Egyptienne 9, p. 439-460.

RousSET M.-O. 1994. Quelques précisions sur le matériel de Hira (céramique et verre). Archéologie Islamique 4, p. 19-55.

Rowley-Conwy P.A., Deakin W.J. \& Shaw C.H. 1997. Ancient DNA from archaeological sorghum (Sorghum bicolor) from Qasr Ibrim, Nubia: Implications for domestication and evolution and a review of the archaeological evidence. Sahara, p. 23-34.

Rowley-Conwy P.A., Deakin W.J. \& Shaw C.H. 1999. Ancient DNA from Sorghum. In M. Van der Veen (éd.), The Exploitation of Plant Resources in Ancient Africa. New York, Kluwer Academic, p. 55-61.

Ruichang xian bowuguan 瑞昌縣博物館 1986. Jiangxi Ruichang faxian liangzuo Beisong jinian mu 江西瑞昌 發現兩座北宋紀年墓 [Deux tombes datées des Song du Nord à Ruichang au Jiangxi]. Wenwu 1986/ 1, p. 70-72.

AL-SAQQĀF 'A. 'U., Mu’jam buldān Hadramawt al-musammā Idām al-qawt fì dhikr buldān Hadramawt, éd. I. A. al-Maqhafī et 'A. H.. al-Saqqāf, Șan'ā', Maktabat al-irshād, 2002, $1^{\text {ere }}$ édition.

SALDERN vON A. 1974. Kunstmuseum Düsseldorf. Glassammlung Hentrich. Antike und Islam. Düsseldorf.

SALDERn vON A. 1980. Glas von der Antike bis zum Jugendstil. Sammlung Hans Cohn, Los Angeles. Mayence.

SASAKi T. 1990. Excavations at A'ali, 1988-89. Proceedings of the Seminar for Arabian Studies 20, p. 111-125.

SASAKI T. 2005. Islamic town sites on the coast of Oman Gulf in the United Arab Emirates, Studies and Essays. History. Archaeology. Geography 25: 39-192.

SASAKI T. \& SASAKI H. 2003. Researches of Khorfakkan Fort on the coast of Oman Gulf, 10th Annual Meeting of the Japan Society for Hellenistic-Islam archaeological studies, Kanazawa, 5-6 July 2003, the Japan Society for Hellenistic-Islam archaeological studies, p. 86-91.

Sauvaget J. (trad.) 1954. Les merveilles de l'Inde. In Mémorial Jean Sauvaget, t.1. Damas.

SAVAGE-Smith E. 1997. Sphero-conical vessels: a typology of forms and functions. In F. Maddison \& E. Savage-Smith (éds), Science, Tools and Magic. Oxford, p. 324-333.

Scalarone D., Lazzari M. \& Chiantore O. 2003. Ageing behaviour and analytical pyrolysis characterisation of diterpenic resins used as art materials: Manila copal and sandarac. Jounal of Analytical and Applied Pyrolysis 68-69, p. 115-136.

SCANLON G. 1971. The Fustat mounds. A shard count 1968. Archaeology 24, p. 220-233.

ScAnlon G.T. \& Pinder-Wilson R. 2001. Fustat Glass of the Early Islamic Period. Finds excavated by The American Research Center in Egypt 1964-1980. Londres.

Schiettecatte J. 2008. Ports et commerce maritime dans l'Arabie du Sud préislamique. Chroniques Yéménites 15, p. 65-89. 
Schiettecatte J. 2012. L'Arabie du Sud et la mer du $\mathrm{III}^{\mathrm{e}}$ siècle av. au $\mathrm{VI}^{\mathrm{e}}$ siècle apr. J.-C. In M.-F. Boussac, J.-F. Salles \& J.-B. Yon (éds), Autour du Périple de la Mer Erythrée. Topoi Supplément 11, p. 237-273.

SChlÜter T. \& GNIELINSKI vON F. 1985. The east African copal. Its geologic, stratigraphic, paleontologic significance and comparison with other fossil resins of similar age. National Museums of Tanzania 8, p. 1-32.

Schottenhammer A. (éd.) 2000. The Emporium of the World. Maritime Quanzhou 1000-1400. Leyde, Brill.

SEDov A.V. 1992. New archaeological and epigraphical material from Qana (South Arabia). Arabian Archaeology and Epigraphy 3, p. 110-137.

Sedov A.V. 2005. The Temples of Ancient Hadramawt. Arabia Antica 3. Pise, Pisa University Press.

Sedov A.V. \& As-Saqqaf A. 1996. Al-Guraf in the Wâdî 'Idim. Notes on an archaeological map of the Hadramawt, 2. Arabian Archaeology and Epigraphy 7/1, p. 52-62.

SerJeant R.B. 1962. Historians and Historiography of Hadramawt. Bulletin of the School for Oriental and African Studies 25, p. 108-133.

Serjeant R.B. 1963. The Portuguese off the South Arabian Coast. Hadramî Chronicles with Yemeni and European Accounts of Dutch Pirates off Mocha in the Seventeenth Century. Oxford, Clarendon Press.

Shaanxi sheng kaogu yanjiusuo 陝西省考古研究所 1998. Songdai Yaozhou yao 宋代耀州窯 [Les officines de potiers de Yaozhou des Song]. Pékin, Wenwu chubanshe.

SHANBAL 2003. Ta'rīkh Haḍamawt al-ma 'rūf bi-ta'rīkh Shanbal. 'A al-Hibshī (éd.). Șan‘ā', Maktabat Șan'ā' al-athariyya.

Shanghai shi bowuguan 上海博物館 2005. Zhongguo gudai baici guoji xueshu yantaohui lunwenji 中國古代白 瓷國際學術研討會論文集 [Les actes du colloque international sur les blancs de Chine]. Shanghai, Shanghai chushu chubanshe.

Al-Shāțirī M. A. 1972. Adwār al-ta'rīkh al-ḥaḍamī. Médine, Dār al-muhājir.

SHEN Y. 沈岳明 2008. Yue yao de fazhan ji Jingliwen chenchuan de Yue yao ciqi 越窯的發展及井里汶沈船 的越窯瓷器 [L'évolution des fours de Yue et les grès à couverte verte des fours de Yue de l'épave de Cirebon]. Gugong bowuyuan yuankan 2008/4, p. 102-106.

Shenzhen bowuguan 深圳博物館 et al. 2012. Xuanse zhimei - Zhongguo lidai heiyou ciqi zhenping 玄色之 美一中國歷代黑婇瓷器珍品 [La beauté du noir - Les chefs d'œuvres des grès à couverte noire en Chine]. Pékin, Wenwu chubanshe.

Shishrina G.V. \& Pavshinskaja L.V. 1992. Terres secrètes de Samarcande. Céramiques du VIII $e^{e}$ au XIII siècle. Paris, Institut du monde arabe.

SHindo Y. 1992. Verre. In K. Sakurai \& M. Kawatoko, Fustat, cité islamique d'Égypte : rapport des fouilles 1978-1985. Tokyo (en japonais), p. 574-658.
SHINDO Y. 2003. Islamic Glass Finds from Raya, Southern Sinai. Annales du $15^{e}$ congrès de l'Association Internationale pour l'Histoire du Verre (New York-Corning 2001). Amsterdam, p. 180-184.

ShIRINSKIY S.S. 2010. Chapitre IX - Les fouilles du Husn al-Ghurab. In J.-Fr. Salles \& A.V. Sedov (dir.), Qāni'. Le port antique du Hadramawt entre la Méditerranée, l'Afrique et l'Inde. Fouilles russes 1972, 1985-1989, 1991, 1993-1994. Indicopleustoi, Archaeologies of the Indian Ocean. Turnhout, Brepols, p. 287-292.

SinClair P. 1982. Chibuene - an early trading site in southern Mozambique. Paideuma 28, p. 149-164.

AL-SīRĀFĪ 2006. Al-șaḥihh min akhbār al-bihāar wa- 'ajā'ibihā. Y. al-Hādī (éd.). Damas, Dār Iqrā' li-l-ṭibā'a wa-l-nashr wa-1-tawzī‘.

SKIK Kh. 1971. La collection de verres musulmans de fabrication locale conservés dans les musées de Tunisie. Bulletin de L'Association Internationale pour l'Histoire du Verre 6, 1971-1972. Liège, p. 87-102.

Sмiтh G.R. 1995. Have you anything to declare? Maritime trade and commerce in Ayyubid Aden: practices and taxes. Proceedings of the Seminar for Arabian Studies 25, p. $127-140$.

Sмiтн G.R. 2008. A traveller in thirteenth-century Arabia: Ibn al-Mujāwir's Tarīkh al-mustabșir. Aldershot, Ashgate.

Soderstrom T.R. 1969. Impression of Cereals and Other Plants in the Pottery of Hajar Bin Humeid. In G.W. Van Beek (éd.), Hajar Bin Humaid. Investigations at a Pre-Islamic Site in South Arabia. Baltimore, Publications of the American Foundation for the Study of Man V, The John Hopkins Press, p. 399-407.

Southeast Asian Ceramic Society 1985. A Ceramic Legacy of Asia's Maritime Trade; Song Dynasty Guangdong Wares and Other $11^{\text {th }}$ to $19^{\text {th }}$ Century Trade Ceramics Found on Tioman Island. Kuala Lumpur, Oxford, Oxford University Press.

Stacey R.J., Cartwright C.R. \& McEwan C. 2006. Chemical characterization of ancient mesoamerican "copal" resins: preliminary results. Archaeometry 48/2, p. 323-340.

Steimer-Herbet T. 2004. Classification des sépultures à superstructure lithique dans le Levant et l'Arabie occidentale (IV et $I I I^{e}$ millénaires avant J.-C.). BAR International Series 1246. Oxford, Archaeopress.

Stein A. 1937. Archaeological reconnaissance in northwestern India and south-eastern Iran. Londres.

STERN S.M. 1967. Râmisht of Sirâf, a Merchant Millionnaire of the Twelfth Century. Journal of the Royal Asiatic Society 1/2, p. 10-14.

Sweeney M. \& McCouch S. 2007. The Complex History of the Domestication of Rice. Annals of Botany 100, p. 951-957.

TAMPOE M. 1989. Maritime trade between China and the West. An archaeological study of the ceramics from Siraf (Persian Gulf), 8th to 15th centuries AD. BAR International Series 555. Oxford, Archaeopress. 
Tengberg M. 2011. L'acquisition et l'utilisation des produits végétaux à Didymoi. In $\mathrm{H}$. Cuvigny (éd.), Didymoi. Une garnison romaine dans le désert Oriental d'Egypte (Praesidia du désert de Bérénice IV). Volume 1. Les fouilles et le matériel. Le Caire, Ifao, p. 205-214.

Tengberg M. 2012. Beginnings and early history of date palm garden cultivation in The Middle East. Journal of Arid Environments 86, p. 139-147.

Tengberg M. sous presse. Vegetation History and Wood Exploitation at Kush (Ras al-Khaimah, UAE), 4th-17th/18th centuries AD. First Results of the Charcoal Analysis. In D. Kennet (éd.), Palaeoenvironmental studies at Kush.

Tengberg M. \& Lombard P. 2001. Environnement et économie végétale à Qal'at al-Bahreïn aux périodes Dilmoun et Tylos. Premiers éléments d'archéobotanique. Paléorient 27/1, p. 167-181.

THAPAR R. 2004. Early India. From the Origins to AD 1300. Berkeley-Los Angeles, University of California Press.

The Oriental Ceramic Society of the Philippines 1993. Chinese and South-East Asian White Ware Found in the Philippines. Singapour, Oxford, Oxford University Press.

TomBer R. 2000. Indo-Roman trade: the ceramic evidence from Egypt. Antiquity 74, p. 624-631.

Trésors Fatimides du Caire 1988. Paris, Institut du Monde Arabe, catalogue d'exposition.

'UMÂRA AL-HaKAmî 1878. Kitâb al-Mufid fì akhbâr Zabîd. In H.C. Kay, Yaman. Its Early Mediaeval History. Londres.

VAllet E. 2010. L'Arabie marchande. Etat et commerce sous les sultans rasulides du Yémen (626-858/12291454). Paris, Publications de la Sorbonne, Bibliothèque Historique des Pays d'Islam 1.

Van Bergen P.F., Peakman T.M., Leigh-Firbank C. \& Evershed R.P. 1997. Chemical Evidence for Archaeological Frankincense: Boswellic Acids and their Derivatives in Solvent Soluble and Insoluble Fractions of Resin-Like Materials. Tetrahedron Letters 38 (48), p. 8409-8414.

VAN DEN BERG K.J. \& BoON J.J. 1999. Recognition of copals in aged resin/oil paints and varnishes. ICOM Committee for Conservation II, p. 855-61.

VAN DER Lith P.A. \& Devic L.M. (éd. et trad. fr.) 1883-1886. Kitāb 'ajā'ib al-Hind/Livre des merveilles de l'Inde. Leyde, Brill.

VAN DER Veen M. (éd.) 2011. Consumption, Trade and Innovation: Exploring the Botanical Remains from the Roman and Islamic Ports at Quseir al-Qadim, Egypt. Frankfurt am Main, Africa Magna Verlag, Journal of African Archaeology Monograph Series 6.

VARISCO D.M. 1991. A royal crop register from Rasulid Yemen. Journal of the Economic and Social History of the Orient 34, p. 1-22.

VArisco D.M. 1994. Medieval Agriculture and Islamic Science: the almanac of a Yemeni sultan. Seattle, University of Washington Press.
Vergara B.S. \& De Datta S.K. 1996. Oryza sativa L. In G.J.H. Grubben \& S. Partohardjono, Plant resources of South-East Asia $n^{\circ} 10$ : cereals. Leiden, Backhuys Publishers, p. 106-115.

Vogt B. 1994. A lost late Islamic port on the south Arabian coast. Bulletin of Archaeology, the University of Kanazawa 21, p. 137-158.

Vosmer T. 2004. Qalhāt, an ancient port of Oman: results of the first mission. Proceedings of the Seminar for Arabian Studies 34, p. 389-404.

WADE G. 2009. An Early Age of Commerce in Southeast Asia, 900-1300 CE. Journal of Southeast Asian Studies 40/2, p. 221-265.

Walshaw S.C. 2010. Converting to Rice: urbanization, Islamization and crops on Pemba Island, Tanzania, AD 700-1500. World Archaeology 42/1, p. 137-154.

WANG Y. 王永平 2005. Sanmingyao 三明窯 [Les fours de Sanming]. Fuzhou, Fujian meishu chubanshe.

WATson O. 2004. Ceramics from Islamic lands. The al-Sabah Collection. Londres, Thames \& Hudson.

Wheeler R.E.M., Ghosh A. \& Deva K. 1946. Arikamedu, an Indo-Roman Trading-station on the East Coast on India. Ancient India 2, p. 17-124.

Wнiтсомв D.S. 1975. The archaeology of Oman: a preliminary discussion of the Islamic period. Journal of Oman Studies 1, p. 123-157.

Wнітсомв D.S. 1978. The archaeology of the al-Hasa oasis in the Islamic period. Atlal 2, p. 95-113.

Wнітсомв D.S. 1983. Islamic Glass from Al-Qadim, Egypt. Journal of Glass Studies 25, p. 101-108.

Whiтсомв D.S. 1988a. Islamic Archaeology in Aden and the Hadramaut. In D.T. Potts (éd.), Araby the Blest. Studies in Arabian Archaeology. Carsten Niebuhr Institute Publication 7. Copenhague, University of Copenhagen/ Museum Tusculanum Press, p. 176-263.

Whiтсомв D.S. 1988b. A Fatimid residence at Aqaba, Jordan. Annual of the Department of Antiquities of Jordan 32, p. 207-224.

Whitcomв D. \& Johnson J.H. 1982. Quseir al-Qadim 1980. Preliminary report. American Research Center in Egypt Reports 7. Malibu, Udena Publications.

Whitehouse D. 1968. Excavations at Siraf: first interim report. Iran 6, p. 1-22.

Whitehouse D. 1975. The decline of Siraf. In F. Bagherzadeh (éd.), Proceedings of the Third Annual Symposium on Archaeological Research in Iran. Téhéran, p. 263-270.

Whitehouse D. 2010. Islamic Glass in the Corning Museum of Glass, vol. 1. New York/Manchester, Corning Museum of Glass/Hudson Hills Press.

Willetts, W. 1981. Introduction. In Southeast Asian Ceramic Society, West Malaysia chapter, Nonya ware and kitchen Ch'ing, Oxford University Press, p.1-16. 
Wong Sh.W.Y. 2006. A Preliminary Study on the Distribution and Consumption of Ceramics in Hong Kong during the Song-Yuan Period. Indo-Pacific Prehistory Association Bulletin 26, p. 140-146.

Wood N. 1999. Chinese Glazes. Their Origins, Chemistry and Recreation. Londres \& Philadelphia, A \& C Black \& University of Pennsylvania Press.

Wood N. \& Kerr R. 2004. Science and Civilisation in China. Volume 5: Chemistry and Chemical Technology. Part XII: Ceramic Technology. Cambridge, Cambridge University Press.

Wright H. 1984. Early seafarers of the Comoro Islands: the Dembeni Phase of the IXth-Xth centuries. Azania 19, p. 13-59.

Wright H.T. \& RAKotoARisoA J.A. 1990. The archaeology of complex societies in Madagascar: case-studies in cultural diversification. In P.J. Sinclair \& J.A. Rakotoarisoa (éds), Urban origins in Eatern Africa: Proceedings of the 1989 Madagascar workshop. Stockholm, Swedish Central Board of National Antiquities, p. 21-31.

XIONG H. 熊海堂 1994. Dongya yaoye jishu fazhan yu jiaoliushi yanjiu 東亞窯業技術發展與交流史研究 [Recherches sur l'évolution et la circulation des techniques de la céramique en Asie orientale]. Nankan, Nanjing daxue chubanshe.

XIONG Y. 熊躍泉 \& He Shiwei 賀世偉 1997. Husi yao chutan 湖泗窯初探 [Recherches sur les fours de Husi]. Zhongguo gu taoci yanjiu 中國古陶瓷研究 vol. 4, p. 219-225.

XuE Q.薛 槷 \& TANG Changpu 唐昌樸 1984. Jiangxi Ganzhou Qilizhen guci yaozhi diaocha 江西贑州七裡鎮 古瓷窯址調查 [Prospections du site des fours de Qili à Ganzhou au Jiangxi]. In Wenwu bianji weiyuanhui 文物 編輯委員會 (éd.), Zhongguo gudai yaozhi daocha fajue baogao ji 中國古代窯址調查報告 [Prospections des sites de fours en Chine]. Pékin, Wenwu chubanshe, p. 124-132.

Yамамото N. 1994. Shifts in the Use of Zhejiang Green Glazed Wares at Dazaifu between the Late Eighth and Fourteenth Centuries. In Ch. Ho (éd.), New Light on Chinese Yue and Longquan Wares. Archaeological Ceramics Found in Eastern and Southern Asia, A.D. 800-1400. Hong Kong, Centre of Asian Studies, University of Hong Kong, p. 169-187.

YubA T. 2005. Chinese Ceramics Found at al-Fustat, Cairo, $9^{\text {th }}$ to $16^{\text {th }}$ Century. Taoci 4, p. 87-95.

ZARINS J. 1989. Arab southern Red Sea ports and the early Chinese porcelain trade as reflected principally from Aththar, 217-108, Saudi Arabia. Annali Instituto Universitario Orientale di Napoli 49/3, p. 231-269.

ZARINS J. \& ZAHRANI A. 1985. Recent Archaeological Investigations in the Southern Tihama Plain (the sites of Athar and Sihi, 1404/1984). Atlal 9, p. 65-107.

ZENG F. 曾凡 1983. Fujian Shunchang Daping linchang Song mu 福建順昌大坪林場宋墓 [La tombe des Song à Linchang (Daping) au Fujian] Wenwu 1983/8, p. 35-49.
ZENG F. 曾凡 2001. Fujian taici kaogu gailun 福建陶瓷考 古概論 [Les recherches archéologiques sur la céramique du Fujian]. Fuzhou, Fujian sheng ditu chubanshe.

ZENG G. 曾廣億 1964. Guangdong Foshan Gusanggang Song Yuan Ming mu jilüe 廣東佛山鼓桑崱崗宋元明墓 記略 [Fouilles des tombes des Song, Yuan et Ming à Gusanggang à Foshan au Guangdong]. Kaogu 1964/10, p. $536-538$ et 528 .

ZENG G. 曾廣億 1985. Guangdong Tang Song taoci gongyi tedian 廣東唐宋陶瓷工藝特點 [Caractères principaux des techniques de la céramique du Guangdong sous les Tang et les Song]. In Fung Ping Shan Museum, Ceramic Finds from Tang and Song Kilns in Guangdong. Hong Kong, Fung Ping Shan Museum, p. 32-62.

Zнао B. 2001. Les officines de potiers de Jizhou au Jiangxi $d u X^{e}$ au XIV siècle. Thèse de doctorat à l'Ecole pratique des Hautes Etudes.

ZhaO B. 2004. L'importation de la céramique chinoise à Sharma (Hadramaout) au Yémen. Annales Islamologiques 38 , p. 255-284.

ZнаO B. 2006. Zhong shiji shiqi maoyi zhongzhuanggang Yemen She'ermai yizhi chutu de Zhongguo ciqi [La céramique chinoise de Sharma au Yémen - un site portuaire maritime médiéval]. In Sh. Zhonghua, X. Chen \& M. Bussoti (éds), Faguo Hanxue, Sinologie Francaise 11 (revue annuelle du Centre de Pekin EFEO). Pékin, p. 79-116.

Zhao B. 2012. Global Trade and Swahili Cosmopolitan Material Culture : Chinese-Style Ceramic Shards from Sanje ya Kati and Songo Mnara (Kilwa, Tanzania). Journal of World History 23/1, p. 41-86.

Zhao B., CARTer R. \& Velde Ch. 2014, 哈伊马角酋长国 佐尔法.努杜德港口遗址出土中国瓷片 [Les tessons de céramique chinoise exhumés sur le site de Julfar al-Nudud, Ras al-Khaimah]. Wenwu 2014/11, p. 33-46.

Zhao B. \& Rougeulle A. 2005. Xiya Feizhou chutu de Changsha yao ciqi 西亞非洲出土的長沙窯瓷器 [Les grès de Changsha exhumés en Asie de l'ouest et en Afrique]. In Zhou Shirong 周世荣 (éd.), Changsha yao 长 沙窑 [Les fours de Changsha], vol. 1. Changsha, Hunan sheng meishu chubanshe, p. 18-26.

Zhejiang sheng qinggongyeting 浙江省輕工業聽 1989. Longquan qingci yanjiu 龍泉青瓷研究 [Recherches sur les grès à couverte verte de Longquan]. Pékin, Wenwu cubanshe.

Zhejiang sheng wenwu kaogu yanjiusuo 浙江省文物考 古研究所, Beijing daxue kaogu wenbo xueyuan \& Cixi shi wenwu guanli weiyuanhui 慈溪市文物管理委員會 2002. Silongkou Yue yao zhi 司龍口越窯址 [Le site de Silongkuo du groupe des fours de Yue]. Pékin, Wenwu chubanshe.

Zhejiang sheng wenwu kaogu yanjiusuo 浙江省文物考古 研究所 2005. Longquan Dongqu yaozhi fajue baogao 龍 泉東區窯址發掘報告 [Rapport des fouilles des sites de fours situés dans la zone dite Dongqu à Longquan]. Pékin, Wenwu chubanshe. 
Zhejiang sheng wenwu kaogu yanjiusuo 浙江省文物 考古研究所 2002. Zhejiang jinian ci 浙江紀年瓷 [Les céramiques exhumées de tombes datées au Zhejiang]. Pékin, Wenwu chubanshe.

Zhongguo guisuanyan yanjiusuo 中國硅酸鹽研究所 1982. Zhongguo taoci shi 中國陶瓷史 [Histoire de la céramique chinoise]. Pékin, Wenwu chubanshe.
Zohary D., Hopf M. \& Weiss E. 2012. Domestication of plants in the Old World: the origin and spread of cultivated plants in West Asia, Europe and the Nile Valley. Oxford, Oxford University Press, $4^{\text {th }}$ edition. 